\title{
THE SPECIFICATION OF EARTHQUAKE RESISTANCE FOR ELECTRICITY SYSTEM EQUIPMENT
}

\author{
H. C. Hitchcock*
}

\begin{abstract}
SYNOPSIS The paper reports the development of earthquake resistance requirements in New Zealand Electricity Department specifications since 1968. It quotes clauses, as issued for high voltage circuit breakers and for power transformers to illustrate the special requirements of brittle structures and of flexibly mounted massive items.

The earthquake clauses for 250MW turbogenerators draw attention to the special susceptability of low tuned supports, while the clauses for the steamraising units emphasise the importance and the difficulties of achieving adequate ductile performance of such large structures during earthquakes.

A method is presented, of choosing seismic design factors for parts of buildings and of appendages according to dynamic and material properties and height above ground.

The paper describes some of the intellectual obstacles for power engineers wishing to achieve adequate understanding of earthquake engineering - the view that "earthquakes are only for Civil Engineers", the idea that a simple, low seismic factor will by itself, ensure resistance to earthquakes, the erroneous concentration on "the frequency of the earthquake", the limited knowledge of many manufacturers and most of all the false assurances of the concept of "factor of safety" when linked to a seismic design code based on the assumption that structures possess ductility.
\end{abstract}

\section{INTRODUCTION}

In 1968 a paper by this author reported work which had been done by N.Z.E.D. under the guidance of Mr. R. I. Skinner of D.S.I.R. to increase the strength of the procelain columns which supported the mercury are valves in the H.V.D.C. inter-island transmission link. Ref.

It also reported that the then almost universal procedure for specifying earthquake resistance for electrical equipment, namely the use of a single low-valued seismic factor applied uniformly to all parts of equipment, would be seriously inadequate in a number of cases.

The paper showed that it was essential to treat the effects of earthquakes as "a matter of dynamic response to random motion" and pointed out the usefulness of "response spectra" in providing graphical solutions to the differential equations of motion. A procedure was outlined for specifying earthquake strength for equipment with brittle components that led to the use of seismic factors very much larger than are commonly used in civil and structural engineering.

The paper dealt very briefly with the probabilities of equipment being subjected to earthquakes and concluded that in New Zealand the smoothed response spectra already used in

* Senior Research Engineer, New Zealand Electricity Department (N.Z.E.D.). the D.S.I.R. Handbook on Tall Buildings (28) were appropriate to guide the earthquake design of major electricity system plant in the more seismically active areas of New Zealand.

Attention was drawn to the anomaly in calculation of overturning moments for rigid structures with medium ratios of height of centre of gravity to width of base.

A warning was given that "rule of thumb" factors can only be "rough and ready". It was claimed by there was sufficient evidence of very large earthquake response by certain equipment under certain circumstances to warrant the use of factors that to some people seemed high. It was-claimed that the cost of following the recommendations was usually small, but if it turned out to be excessive the remedy was straightforward: do the necessary engineering analysis and experiment to show that a lower factor can be used to obtain the target result.

\section{DEVELOPMENTS SINCE OCTOBER 1968}

\subsection{Recommendations of 1968 Paper}

It is interesting to examine the actions which the paper suggested were necessary:

"1) The N.Z. Electricity Supply regulations "strength" clause No. 61 should be amended to provide separate and appropriate seismic factors for plant instead of including it in the $1 / 6 \mathrm{~g}$ requirement along with power and substation buildings."

No change has been made so far.

Bulletin of the N.Z. Society for Earthquake Engineering, Vol.6, No.4 December 1973 
"2a) The Standards Association should incorporate a strong warning in N.Z.S.S. 1900 Chapter 8 that structures with dynamic and material characteristics different from buildings must have seismic design factors separately determined as they will in most cases be larger than those used for buildings."

The December 1970 amendments to N.Z.S.S. 1900 Chapter 8 contained some additional and some amplified provisions for "parts of buildings" to guard against resonant amplification and lack of ductility, but still contained no warning to other engineers of the possible inadequacy of trying to fit "Building Codes" to other types of structure.

"2b) The Standards Association should ask their loadings committee to reconsider Table 5 in view of the anomalies revealed by 'Fig. 8 with regard to holding down bolts for base-mounted equipment of medium ratio of height of centre of gravity to base width."

The December 1970 amendments to N.Z.S.F. 1900: Chapter 8 included a reservation (Item 13 of Table 5B) that "connections for items 8 to 12 inclusive shall be designed for the specified forces provided that the gravity effects of dead and live loads shall not be taken to reduce these forces." This is the Loading Committee alternative to the author's recommendation that transformers and other equipment mounted above ground on separate supports should be designed with a seismic factor of .75 .

Both of these provisions produce very roughly the desired result i.e. they prevent people reaching the conclusion that equipment of certain proportions need not be secured by holding down bolts; however, the $3 / 4 \mathrm{~g}$ requirement becomes excessively costly if applied uncritically to larger sizes of equipment and the "no dead load" requirement results in excessively large holding down bolts in items with low centre of gravity. These provisions also illustrate that "simple" rules to cover a wide range of dynamically different situations can only be crude approximations.

The Department's current specifications for turbo-alternators (sect. 4.3) and Steam Boilers (sect. 4.4) contain a compromise version requiring that not more than half the gravity effect of dead load be allowed to reduce seisurcally induced stresses.

"2c) The Standards Association should include warning that in seeking guidance for items not listed in Item 5 establishing similarity of name may be quite misleading - similarity of size and structural nature is the only acceptable comparison."

The December 1970 amendments contained no comment - but the point is not well expressed. It was intended to convey the author's concern about the inadequacy of factors for parts of buildings listed without regard to the natural periods of vibration of the part or of the building, whether its failure would be ductile or brittle and what level in the building it is mounted. The amendments to the loading code currently under discussion do take these into account.

"3) The Standards Association should initiate the preparation of an earthquake loading design code for plant and structures other than buildings ......"

The author was in error. The standards
Association can only respond when the needs of an industry are expressed and active support is offered. In the absence of joint expression of such a need, the N.Z.E.D. has in effect had to draw up its own codes.

"4) The major employers of electrical engineers should consider establishing short study courses on earthquake design ..... directed to the special needs of electrical and other engineers ....."

Only limited action on these lines has been possible within N.Z.E.D. so far, but the Research Section has given assistance and advice to other sections as far as its limited manpower resources allow.

A project to which the Department's staff has contributed is a brief survey of seismic design methods as applied to nuclear reactors. which is being produced by a Working Group of the N.Z. Atomic Energy Committee. The survey illustrates two points of difficulty in training staff to look after earthquake requirements -

(i) the 110 pages are in effect a literature study of some 80 references which are a minute fraction of the total available. This indicates the vast ground work which must be covered by a beginner - a large task for someone with a sound grasp of structural dynamics and an impossible task for anyone without.

(ii) the group is having difficulty terminating the study because of the rapid inflow of new and relevant information.

"5) Seismic design factors along the lines suggested should be used until long term measures can be put into effect."

Earthquake clauses have now been included in N.Z.E.D. purchasing specifications whenever they are appropriate and it can be claimed that practically all equipment being installed in the Department's system is earthquake resistant. It is not of course earthquake proof. Some damage can be expected in severe earthquakes, but it should not be large even in the areas of strongest shaking and should not extend over a large area.

A large amount of existing equipment has been examined and many obvious weaknesses strengthened. There are, however, many circuit breakers purchased some years ago which still require modifying as do a number of items of H.V.D.C. equipment. This work still awaits suitable manpower availability.

\subsection{The San Fernando Earthquake 9 Feb. 1971}

The San Fernando earthquake in Feb. 1971 taught three major lessons, according to David J. Leeds, Ref. 2

"1. In the future, the emphasis in earthquake-resistant design must be on providing uninterrupted service of community lifelines, including utilities, communications, transportation, fire and hospital service. Failure of the community lifelines poses a threat to human survival and to community operation.

2. Earthquakes of moderate magnitude ( $6 \frac{1}{2}$ Richter or larger) can have ground accelerations as high as $0.50 \mathrm{~g}$ ( 0.5 times the acceleration of gravity.)

3. The "advanced" technique of aseismic design criteria in vogue for the past ten years - response 
spectra - is no longer acceptable. It only tells half the story. Time-history design and analysis is now required for important structures."

The damage caused by this earthquake demonstrated many times over the points made in the author's 1969 paper. Amongst the most spectacular damage was the devastation which occurred at sylmar in the newly completed southern terminal of the $800 \mathrm{kV} 1440 \mathrm{MW} \mathrm{H.V.D.C}$. transmission link for which the traditional $0.2 \mathrm{~g}$ uniform seismic design factor had been specified. The damage was severe, putting the link out of service for nearly 18 months and causing damage said to be in the region of $\$ 28$ million.

One notable exception amongst the general damage was the group of porcelain columns supporting the 15,0001b mercury arc valves. None of these failed and the consulting engineers who investigated the failures on behalf of the Bonneville Power Administration which owns the other end of the D.C. transmission system concluded that the columns had appropriate strength and "were an excellent example of sound antiseismic design". Ref. 3.

It is interesting to note that Limseth and Skoglund who were involved in the design of the valve supports presented a paper to the I.E.E.E. in 1969, Ref. 4, which described the antiseismic design of structural porcelain on the lines advocated in the author's 1969 paper.

The consultants examination of the equipment which failed was very thorough and far more detailed than any studies yet carried out in New Zealand. For the few very simple structures like the valve supports they used response spectra which they estimated would represent the ground shaking during the earthquake. For all other structures they used their computer program which applied to a mathematical model estimated acceleration time histories of the two horizontal and the vertical components of the ground shaking, simultaneously.

For each item of equipment studied, they computed a factor of safety during the estimated earthquake. All items with a calculated factor of safety of less than 1 were those which had failed and those with a f.o.s. greater than 1 had survived. This is clear indication that the skills and techniques necessary for adequate understanding of earthquake design of these special types of equipment, do in fact exist, but the 300 page report and its companion volume of calculations, together with the eight volumes of computer output give an indication of the manpower and resources necessary to carry out the study.

The damage at Sylmar was typically a failure of porcelain columns in bending. One other important mode of failure was in equipment supported by $V$ strings of tension insulators. These were stable against the low forces of the original seismic design load $(0.2 \mathrm{~g})$, but when subjected to forces larger than this in the actual earthquake, the strings were alternately unloaded and reloaded until they broke in tension under the repeated shock. Brittle castings, faulty welding and inadequate anchor bolts also contributed to failures.

\section{EARTHQUAKE RESISTANCE}

\subsection{Basis of Policy}

The basis of N.Z.E.D.'s current practice can be summarised thus -

Design Aim. All equipment essential to continuity of supply is to survive a design earthquake without requiring major repair. All minor equipment and stores are to be given similar earthquake resistance wherever this can be done cheaply and easily.

Design Earthquake. Since the whole of New Zealand is smaller than the active zone of major earthquakes such as have occurred in Chile, California, Alaska; one design earthquake is used for all localities at present. This is defined by a set of single body response spectra Fig. (1) being the averaged and smoothed spectra from the eight components of $\mathrm{El}$ Centro 34 and 40 , Taft 52 and Olympia 49, "weighted" up to the general level of El Centro $40 \mathrm{~N}-\mathrm{S}$

Modifications to recognise specific site characteristics are being introduced for the first time for some of the Huntly power station equipment. (see "turbo alternator" and "steam raising equipment".) This can only be done for plant and equipment which remain always on a specific site - equipment subject to transfer must be purchased with the maximum strength requirement.

Design Measures. Recognising that seismic design factors for plant and equipment with brittle components or machined parts which will not tolerate deformation, may have to be very much longer than those used for building structures, seismic design factors are derived from first principles for each class of equipment -

1) by reading from a set of design earthquake response spectra, the acceleration response of an elastic body with the same natural period and damping, then

2) - providing sufficient strength or - providing sufficient ductility or - providing sufficient damping.

"Sufficient strength" for equipment with brittle components, low damping and natural periods between about .2 and .4 seconds, may require seismic factors up to 10 or more times as large as those used for buildings.

"Sufficient ductility" can reduce seismic design factors to the levels used in buildings but satisfactory behaviour in repeated loading beyond yield point must be clearly understood and estimated.

"Sufficient damping" in the form of specifically designed shock absorbers can be very economical for equipment of high importance or high value (such dampers up to 2 million pounds force capacity are advertised for use in nuclear power stations).

\section{2 Outdoor Circuit Breakers}

Section 4.1 gives the specification clauses setting out N.Z.E.D.'s present earthquake requirements for outdoor (High Voltage) Circuit Breakers. The following points should be noted:

(i) for circuit breakers which are of a simple construction a very simple approach is provided which requires a seismic design factor related to the degree of damping (see drawing Z5396) (Fig. 2) irrespective of the natural period of vibration. This is very rough but very simple 
and was very suitable for manufacturers who were unfamiliar with earthquake design procedures.

(ii) the requirement for more sophisticated methods of analysis for more complex constructions reflects the growing capability and experience of manufacturers in their methods of testing and analysis.

(iii) attention is drawn to the fact that there is little point in glving a supporting structure a yield strength much higher than the fracture strength of the critical porcelain.

It will be noted that earthquake loading is to be considered in only one direction at a time. Earthquake stresses in ary particular direction at any particular site can be evaluated in terms of an inverse relacionship of magnitude and probability which can however be only vaguely indicated. The increase in risk of damage due to the combined effect of earth quake motion in all three directions is in principle calculable but even more vaguely. Thus, it is essential to considex carefuliy whether the great increase in calculation complexity necessary to allow for simultaneous effects of all components is warranted by the ill defined gain in estimating an already ill defined risk. The N.Z.E.D. specification is based on the view that for most electrical equipment, design loads of fairly large magnitude, considered one at a time, are simpler and more economical for a manufacturer to use and for a purchaser to adjudicate than lower loads appplied in complex manner.

A method of improving the earthquake resistance of existing circuit breakers with weak porcelain columns was described in ref. (1). This used cantilever legs to support the tank of the circuit breaker, flexibly enough to give it a natural frequency of about $2 \mathrm{~Hz}$. In Ref. (5) Winthrop and Hitchcock studied the response of this arrangement to different earthquakes and with different degrees of damping. Fig. 4 shows the circuit breaker outline, the mathematical model as a two body problem and the differential equations of motion. Fig. 5 shows how the acceleration response varies with damping type, damping magnitude and earthquake size. Fig. 6 defines the types of damping studied namely, "viscous" damping i.e. force proportional to velocity, "velocity squared" i.e. force proportional to the square of the velocity and "coulomb or friction" damping i.e. force constant except at zero velocity.

Our earliex circuit breakers of this type have an ultimate strength equivalent to nearly $0.6 \mathrm{~g}$; the curves suggest they would probably be protected, although without much margin from an "El Centro $40 \mathrm{~N}-S^{\text {" }}$ sized earthquake by this type of mounting fitted with $40 \%$ equivalent of any of the three kinds of damping. Later nodels of the same breaker with porcelain twice as strong would be reasonably protected from an earthquake half as large again.

Fig. 7 shows the maximum displacement of the circuit breaker tank body for the same parameters and indicates the amount of movement which must be accommodated by the springs and the dampers. This shows that the \pm 1.5 inches total movement allowance derived by very elementary methods in 1968 was equal to the actual displacement derived by the computer study. It, therefore, should have its movement allowance increased to say \pm 2.5 inches to permit it to give protection to the double strength version of the breaker up to 1.5 times the "El Centro" sized earthquake.

However, the study also shows that "velocity squared" dampers are almost equally effective. It should be noted that oleo-dampers with exactly the characteristics required are avaliable almost off the shelf in custom built sizes from local air automation companies. A possible alternative would be the use of the steel deformation type of damper described by skinner in Ref. (6).

\section{3 other structures containing porcelain}

In Ref. (7) Gilmour and Hitchcock describe the design of a yielding structure to add earthquake resistance to the procelain columns supporting the 80 tonne $250 \mathrm{kV}$ smoothing reactors in the H.V.D.C. system; using Prof. Jenning's yield-ratio response spectra, Ref. (8), Jennings and Husid study on the collapse of yielding structures, Ref. ( 9 ) and Bertero and popov's study of Alternating strains in Steel Beams Ref. (10), Fig. (8) shows diam gramatically the original structure supported on 4 rigid porcelain columns $2.3 \mathrm{~m}$ tall, the modified arrangement in which steel beams with carefully calculated yield characteristics were introduced so that plastic hinges would form and absorb earthquake energy before bending moments reached breaking load on the porcelains.

Fig. (9) shows force-deflection hysteresis loops from the calculated response of the structure to the $E I$ Centro $40 \mathrm{~N}-S$ earthquake motion.

\subsection{Outdoor Oil Immersed Power Transformers}

Section 4.2 gives specification clauses setting out the Department's present earthquake requirements for transformers. They are based on measurements which showed that common transformer installations have sufficient flexibility, partly in foundations, partly in under-carriages and sufficiently low damping, to make them strong amplifiers of earthquake motion. (i.e. a number of transformers showed a natural period of about .2 sec).

The $.75 \mathrm{~g}$ seismic design load is chosen because of the high response of such transformers to the design earthquake even in foundation deformation raises apparent damping to about $10 \%$ of critical and is higher than required by normal structural considerations in order to reduce severe shock loading on porcelain bushings consequent on yielding of holding down bolts.

The $1.5 \mathrm{~g}$ requirement for appendages reflects the very high earthquake responses experienced by lightweight appendages to large masses when their natural periods of vibration are similar.

Where foundations and transformer undercarriages are known to be very rigid or where transformers without wheels are mounted direct on rigid ground level slabs, comparable security can be obtained with seismic design load as low as .49 .

We believe that transformers are another 
example of plant where it is not possible to "define an earthquake and leave it all to the manufacturer". The 1969 paper shows and later measurements confirm how flexible a number of our transformers were found to be and since a part of this flexibility is entirely beyond the knowledge and control of the manufacturer it is the purchaser who must decide what level of seismic design factor is necessary to cover all the varying local conditions in which transformers may be installed.

N.Z.E.D.'s wish to mount transformers on wheels in order to continue the existing handling policy means that flexibility of wheels is added to that of foundation pads and the measured natural period of many of our transformers is in the order of $.15 \mathrm{sec}$. to $.2 \mathrm{sec}$.

If it could be shown that such wheels and axles are capable of "ductile yielding to four or five times their yeild point deflection" then a relatively low seismic factor could be considered as in normal structural design but the question would have to be asked, "Can such yielding of wheels and axles be designed to take place smoothly and without shock loading to transformer bushings and without risk of serious collapse?". The concept of "Ductile" wheels and axles is just too difficult to contemplate, and we therefore require our transformer design to survive the design earthquake elastically. As explained in Ref (1) this requires a seismic factor of the order of $.75 \mathrm{~g}$.

\subsection{Turbo-generators on low-tuned supports}

Section 4.3 sets out the earthquake clauses for the $250 \mathrm{MW}$ turbo-generator sets for Huntly power station.

The growing size of turbo-generators has led to the adoption of the low-tuned support structure with a natural frequency of vibration in the vicinity of 3 to $5 \mathrm{~Hz}$. This is in the region of maximum response to most earthquakes and even at Huntly where the groundshaking is likely to have a predominant period in the region of say 1 second, it is believed there will be a substantial effect in the 3 to $5 \mathrm{~Hz}$ range as usual.

Ground motion studies are being carried out, but for this specification a set of design spectra has been created by multiplying the "acceleration" values of our normally used "E1 Centro $1940 \mathrm{~N}-\mathrm{S}$ " based spectra by 0.8 , multiplying the scale values for period by 2 and regarding structures with natural frequencies above $10 \mathrm{~Hz}$ as being "rigid", i.e. experiencing very little amplification of earthquake motion.

\section{This procedure indicates an expectation of:}

(i) a relative lowering of maximum ground surface motion in very strong earthquakes because the soil is not strong

(ii) a general shift of the peaks of the response nearer to a period of one second because of the depth and flexibility of the soil on the site above bedrock.

(iii) a slight reduction of the higher frequency components.
A preliminary study by M.O.W. of the probability of occurrence of ground motion of different magnitudes suggests that acceleration of basement rock at this site could reach $0.1 \mathrm{~g}$ about once per 1000 years on the average and suggests that this is a suitable probability for design of a 200 million dollar investment. The response spectra chosen imply that the effect of the complicated influences of soil and foundation characteristics will result in an amplification of this base rock motion to slightly more than $0.3 \mathrm{~g}$ at the foundation slab of the station.

The specification calls for:

(i) identification of modes of vibration in the major structures

(ii) estimation of the response of such modes and of the resulting stresses in critical components.

It draws attention to a number of points to be especially watched in connection with low-tuned supports and with thrust bearings, machine anchorages, condenser arrangement, main pipe work, and spring mounted equipment (large and small).

\section{$3.6250 \mathrm{MW}$ Steam Raising Units}

Section 4.4 is part of N.Z.E.D. specification for the steam raising units at Huntly.

The specification asks manufacturers to take note of the poor performance of several types of equipment in recent earthquakes and to confirm the earthquake design capability of their structural designers and steam unit designers.

It is appreciated that large, efficiently running organisations in non-earthquake countries may find it hard to introduce earthquake considerations in their design philosophy, but is is expected that the implication of earthquake failures, particularly in the San Fernando earthquake, will, by now, have been appreciated by a wider audience than those immediately concerned.

The specification asks for the design of the structural work to be based on the pseudodynamic methods set out in N.Z.S.S. 1900: Chapt. 8, but with a $\mathrm{K}$ factor slightly reduced $\left(\mathrm{K}_{\mathrm{A}}=0.9\right)$ for fully ductile "moment resisting space frame structures without cross bracings" and a slightly increased $\left(\mathrm{K}_{\mathrm{A}}=1.2\right)$ for "fully crossbraced structures".

It requires the use of a steelwork design code which recognises fully the requirements for satisfactory plastic hinge performance.

The specification asks for preliminary estimates of the degree of overstrength contained in the structure to indicate the accelerations likely to be reached by the top of the structure in minor earthquakes. It asks for preliminary estimates of the natural frequencies of the first modes to help identify which plant items may be subject to double resonance effects. It asks for estimates of accelerations corresponding to the fully yielded condition, to ensure that the problems of designing earthquake resistance into braced structures are fully considered. 
The specification asks tenderers to describe their experience in earthquake design using their proposed type of steel, to ensure that the problems of obtaining steels with adequately controlled composition and properties, particularly weldability and notch ductility, are adequately recognised. Such experience would also relate to arrangements for providing the high levels of supervision and inspection necessary to achieve satisfactory quality of design, fabrication and site installation and construction.

Foundation loads are to be stated for normal conditions and for full yielding. This is to ensure that the implications of plastic hinge design particularly at column bases are fully identified.

The successful tenderer is to check the structure for significant modes of vibration. In plant of this nature the main structure is so robust that any modes of vibration other than the first are almost certainly associated with some specific portion of the plant e.g. furnace walls, tube banks etc. and would be dealt with as individual items.

A general indication of the kind of earthquake ground motion which the plant is intended to withstand has been estimated as described in section 3.5 and set out on drawing 25590, Fig. 10. This includes an estimate for the vertical component of ground motion and tenderers attention is drawn to possible vertical response of suspended items e.g. the main furnace, steam drum, etc.

However, for parts of the structure and for plant and equipment mounted in the structure, seismic factors generally similar to but slightly varying from Table 5B of N.Z.S.S. 1900: Chapt. 8 are set out in Table II of the specification in order to give greater recognition to the dynamic properties of the items concerned, and to take account of the height in the structure at which they are mounted. This, to some extent, anticipates the revision of Chapter 8 which is in progress but which is not ready yet.

Attention is drawn to an alternative expression of the formula in Glause 8.36.3.1 for the distribution of total lateral force over the height of the building which appears to be more meaningful namely - the design acceleration of a "part" is equal to the design acceleration of the "whole" multiplied by the ratio of "the height of the part" to "the height of the centre of gravity of the whole". This allows $k_{x}$ to be extended to apply to appendages to the main structure at height $h_{x}$ above ground thus: $-\mathrm{K}_{\mathrm{x}}=\mathrm{N}$. $\left[\mathrm{h}_{\mathrm{x}} / \mathrm{h}_{\mathrm{cg}}\right], \mathrm{K}_{\mathrm{A}}$ where $\mathrm{N}$ is a number equal to $1,2,3$ or 6 according to the dynamic category of the item concerned. Dynamic categories are defined instead of the existing arrangement in Table 5B of listing items by name.

This procedure is expressed graphically in Fig. 11 where it will be noted that the "triangular" distribution of acceleration which is used for calculating bending or overturning moments for the structure as a whole is not applicable to individual parts or appendages fixed to the structure below about mid height. Such items will be subjected to much the same acceleration as objects which are attached to the ground and their design factors are expressed by the factor $\mathrm{K}_{\mathrm{B}}$.

The procedure is the logical extension to "items attached to buildings" of the introduction in 1965 of the "triangular distribution of base shear" for the main structures themselves.

Reports of damage to lift machinery in Wellington 1968 ref (11) and Los Angeles 1971 ref (12) and to building services Alaska 1964 ref (13) make the need for this clear enough.

These rules are only approximate, but they go part of the way in safe-guarding equipment against multiple amplification described in the author's 1969 paper and illustrated in Fig (12) from ref. (22). Some special points are mentioned in connection with boiler internals, pipework, anti-vibration mountings and axial shock loading in horizontal machines.

\section{SPECIFICATION CLAUSES FOR EARTHQUAKE RESISTANCE}

\subsection{Part of N.Z.E.D. Specification for} outdoor High Voltage Circuit Breakers

" EARTHQUAKE PRECAUTIONS

The circuit-breakers and associated equipment will be installed in areas subject to earthquakes and they shall be designed to withstand, in working order and without excessive displacement, the stresses arising from the following loads:

(a) Weights of component parts

(b) Pressure of working fluid

(c) Reaction of moving parts and all other loads arising during operation up to the rated capacity (including short-circuit current effects).

(d) Pull of connections on terminals, combined with whichever of the following gives the most adverse combinations

(i) Wind Loads

(ii) Earthquake-induced horizontal loads

(iii) Earthquake-induced vertical loads

\section{Design Loads}

The loads used in design calculations shall be not less than the following:

\section{(a) Pull of Conductors}

1000 Newtons horizontally in any direction except for equipment with an interrupting rating less than $1000 \mathrm{MVA}$ when the pull may be $500 \mathrm{~N}$.

(b) Winc Loads

$900 \mathrm{~N} / \mathrm{m}^{2}$ on all cylindrical surfaces $1500 \mathrm{~N} / \mathrm{m}^{2}$ on all other surfaces acting horizontally in the most adverse direction.

(c) Earthquake-induced Horizontal Loads

If the equipment offered is of simple construction, having no modes of vibration other than its first in the range $1 \mathrm{~Hz}$ to $10 \mathrm{~Hz}$ then the earthquake stresses may be determined on the following approximate basis; 
A load acting in the most adverse direction equal to the weight of the equipment (or appropriate protion of the equipment) multiplied by a: seismic factor. This load may be assumed to act at the centre of mass of that portion of the equipment which is above the point at which stresses are being studied.

For equipment which will fail by fracture of a brittle component the seismic factor shall be not less than 1.5 (but see Note following next paragraph).

For equipment in which failure under earthquake loading is in other than brittle components a seismic design factor not less than. $75 \mathrm{~g}$ shall be used (but see Note).

Note: Where the inherent damping of any item of equipment complete with its supports has been determined, a. design factor not less than that given in drawing Z5396 (Fig. 2) for the appropriate value of damping may be used.

If, however, the equipment is of complex construction and has two or more modes of vibration within the range $\mathrm{I} \mathrm{Hz}$ to $10 \mathrm{~Hz}$ then design loads shall be determined by one of the following methods or a valid equivalent;

(i) Representing the equipment by an appropriate number of masses coupled by springs and dampers and using the method of modal analysis.

(ii) Representing the equipment by appropriate masses coupled by springs and dampers and using methods of direct integration to determine its responses to several earthquake motions having the same general characteristics as are implied by the smoothed averaged acceleration response spectra given in drawing $F 9018$ (Fig. 3).

(iii) Subjecting a full size or a scale model of the equipment to tests on a shaking table, reproducing the motion of several earthquakes having the same general characteristics as are implied by drawing F 9018 (Fig. 3).

\section{(d) Earthquake-induced Vertical Loads}

(Applicable only to components with natural frequencies of vibration between 5 and $20 \mathrm{~Hz}$ especially those forming horizontal or sloping cantilevers or beams).

A load acting vertically downwards or upwards at the same time as the normal weight, assumed to act through the centre of mass of that portion of the equipment beyond the point at which stresses are being studied and to be equal to 1.5 times the relevant weight.

\section{Design Stresses \& Factors of Safety}

In calculations regarding earthquake strength of porcelain or other brittle components, the adopted designed maximum stress shall provide a factor of safety of not less than 2 on a guaranteed failing strength which shall not exceed "the average tested strength less three standard deviations". If actual test results are not available for a statistical determination of strength then higher factors of safety shall be used.

In earthquake strength calculations for other parts of the circuit-breaker normal working stresses shall be used except that where there is clearly little to be gained in making the yield load of a supporting structure much larger than the fracture load of the porcelain, a design may be modified accordingly.

\section{Information and Tests}

Tenderers shall state which component or components determine the earthquake strength of the circuitbreaker or other equipment and shall submit a summary of their calculations by which this strength was established. The calculations shall show the design stresses and factors of safety used and the mode of failure to which these are related (e.g. fracture, bending, overturning, failure to operate, etc.). Tenderers shall submit a drawing showing the weight and location of centre of gravity of the principle components of each piece of equipment.

Tenderers shall submit reports on any tests in which damping factors have been established and these shall show the associated natural periods of vibration.

Tenderers shall describe tests or studies they have done or propose to do to prove the earthquake resistance of the equipment offered."

\subsection{Part of N.Z.E.D. Specification for Power Transformers}

\section{"EARTHQUAKE PRECAUTIONS}

The transformers will be installed in areas subject to earthquake and they shall be designed to withstand in working order a severe earthquake.

The response of a transformer to earthquake movement is determined primarily by the flexibility and damping characteristics of the foundations on which it is mounted. As these vary according to local conditions the transformers shall be designed to withstand, without normal working stresses being exceeded, the following nominal earthquake loads in addition to loads present during normal operation:

(a) For main structural components including undercarriage, wheels and anchoring attachments, a horizontal load acting in any direction corresponding to its own weight multiplied by a seismic design factor of 0.75 , acting through the centre of gravity of the transformer and separate associated radiator bank if provided.

(b) For all appendages to the main tank and separate associated radiator bank including radiators, conservator tanks, pipework and electrical bushings but excluding Buchholz relays:

(i) A horizontal load acting in any direction and corresponding to a seismic design factor of 1.5 .

(ii) A vertical load, i.e., a load acting downwards added to the weight of the equipment or its components and equal to the weight multiplied by a seismic design factor of 1 .

(c) Buchholz relays or any other device arranged to trip the transformer from service automatically whether mounted on the transformer or elsewhere shall not falsely operate when subjected to a sinusoidal vibration producing a maximum acceleration up to $2 \mathrm{~g}$ at any frequency between 1 and $10 \mathrm{~Hz}$.

Note

(i) The horizontal and the vertical earthquake loads may be considered separately not simultaneously.

(ii) The following loads normally allowed for in the design of transformers need not be considered as acting at the same time as the earthquake design loads: vacuum load, transport shock and vibration, wind load (if applicable).

Special consideration shall be given to fastening the core and other components inside the tank and 
Tenderers shall confirm specifically that the core will not be able to move within the tank and cause damage to connections, bushings, and other components.

Each transformer, when mounted in its normal service position as shown on the job specification drawings, will be tied down to the rails on which it stands to prevent relative horizontal or vertical movement between the transformer and the rails under earthquake shock. Four or more suitably positioned attachment points shall be provided on the transformer tank and also on the frame of any separate associated radiator bank. Removable links shall be provided to connect between these attachment points and suitable positions on the rails which will be British Standard $851 b$ flat bottom. The links shall incorporate provision for adjustment in length to ensure that any transformer and/or separate associated radiator bank can be interchanged with any transformer and/or separate associated radiator bank of the same size supplied under the same contract, and for tensioning to eliminate shock in joints. Drilling of the rail web for the attachment of these links will be accept able. Links securing separate associated radiator banks to the rails shall be fastened so that vertical movement of such radiator banks relative to the rails is prevented but small horizontal movements can take place. Struts or other suitable couplings shall be provided between the transformer tank and the mounting frames of separate associated radiator banks. These struts shall be so placed and sufficiently strong to prevent relative horizontal movement between the transformer and separate associated radiator banks which would damage the oil pipe flexible connections.

\section{Tenderers shall in their tender:}

(a) State which component or components determine the earthquake strength Iimits of the transformer and shall include a summary of the calculations by which this strength was established.

(b) Include a drawing showing the weight and location of centre of gravity of the major components of the equipment.

(c) Include evidence that Buchholz relays and other tripping devices comply with the vibration requirements."

\section{"Buchholz Relays}

The recommended relays are A.S.P.E. type SOS-EE-DR (aseismatic version) with fixed reed contacts and moving magnets, and fitted with a test-cock threaded $1 / 4$ in BSP for air-injection testing of the trip-switch. Type tests are not required for these relays, which are supplied by:

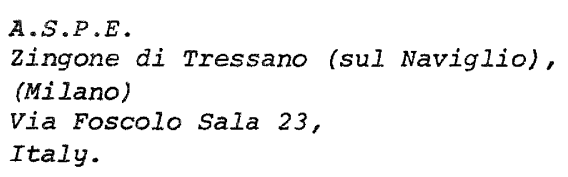

Any alternative Buchholz relays offered must not operate due to movement of the transformer resulting from earthquake forces. Tenderers shall give full details of these alternative relays in their tender including type tests proving that maloperation of the relays will not occur up to the limits specified above. Magnetically-operated dry reed contacts are preferred."

\subsection{Part of N.Z.E.D. Specification for $250 \mathrm{MW}$ Turbo-generators}

\section{"EARTHQUAKE DESIGN}

\section{Resistance to Earthquakes}

The equipment supplied under this Contract shall be designed to have substantial resistance to earthquakes. This will require allowance in the design of the plant, its components and supporting structures, for seismically induced accelerations ranging from $0.3 \mathrm{~g}$ to $1.0 \mathrm{~g}$ or more depending on:

(a) natural period and mode of vibration

(b) Damping (inherent or specifically provided)

(c) manner of failure (ductile or brittle)

(d) importance (consequences of failure)

\section{Design Earthquake Motion}

It is desired that the plant shall be capable of surviving without major damage a ground motion implied by the single body response spectra given in drawing z 5590 (Fig. 10).

\section{Vibration Modes}

Tenderers shall therefore identify, for the "As Installed" condition of all major equipment offered, any modes of vibration which have a frequency less than $10 \mathrm{~Hz}$ horizontally in any direction and less than $15 \mathrm{~Hz}$ vertically.

They shall estimate using the response spectra provided or by other equivalent method agreed upon with the Engineer, the acceleration response induced in each such mode by the defined earthquake motion, and the corresponding maximum stresses in those parts or components which are critical for continued operation or for structural integrity.

\section{Direction and Combination of Earthquake Loads}

Loads corresponding to the horizontal response shall be considered as acting in any horizontal direction and those corresponding to the vertical response shall be considered as acting either upwards or downwards in addition to normal weight.

For this Contract the two horizontal and the vertical components of earthquake load may be considered non-simultaneously but manufacturers whose facilities and experience are sufficiently sophisticated, are invited to comment on any likely adverse combinations of these loads in an actual earthquake situation when all three components of the earth's motion act simultaneously.

\section{Design Stresses}

Stresses caused by the specified earthquake loads shall be combined with those occurring in normal operation and the resulting maximum stresses shall:

(a) be less than one third of the ultimate strength of brittle materials or non-ductile types of construction

(b) preferably be less than yield stress in ductile materials.

\section{Ductility}

If the maximum stresses calculated assuming linear stiffnesses in structures and components exceed yield stresses, the equipment may still be acceptably earthquake resistant if it is capable of repeated ductile yielding in alternate directions with displacement up to 4 or more times those at yield point provided that such yielding:

(a) does not damage rotating parts

(b) does not damage other vital components such as bearings, seals of any precision-machined parts, or highly stressed components 
and that such damage as may occur is repairable with ordinary equipment and material in a reasonably short time.

\section{Special Requirements}

In applying the foregoing requirements, Tenderers shall take particular care regarding the following -

\section{Low Tuned Supports}

If the supports for the turbo-generator have stiffness which gives a natural frequency of vibration in the vicinity of 3 to $5 \mathrm{~Hz}$ and the inherent damping is found to be about $1 \%$ of critical, then the response of the turbo-generator to the specified earthquake would be approximately $1.5 \mathrm{~g}$ with a supporting structure which remains elastic.

Tenderers are invited to consider the following methods of designing an installation which will survive the design earthquakes without experiencing such high accelerations:

(a) if the steel support columns are properly detailed to provide adequate ductility then support columns which start to yield when the induced acceleration in the machine platform reaches $0.3 \mathrm{~g}$ would be acceptable. They would limit the machine acceleration to 0.4 or $0.5 \mathrm{~g}$. (See "Equipment mounted on $\mathrm{T} / \mathrm{G}$ Table".)

(b) if the flexibility is provided by steel coil springs the addition of hydraulic dampers to provide $10 \%$ of critical damping would reduce the response to about $0.75 \mathrm{~g}$. With $20 \%$ of critical damping the response would be about $0.5 \mathrm{~g}$.

(c) if a support structure for the turbo-generator designed to give an "as installed" natural frequency of not less than $10 \mathrm{~Hz}$ or preferably $12 \mathrm{~Hz}$ in any horizontal direction is compatible with the machine design, it would almost eliminate earthquake amplification and would require less rigorous detailing for ductility. A design reaching yield point at $0.3 \mathrm{~g}$ would survive the design earthquake elastically and would subject the machine to little more than $0.3 \mathrm{~g}$ maximum acceleration.

\section{Ductility in Turbo-generator Supports} that -

Adequate ductility in the support columns requires

(a) the columns must be capable of forming plastic hinges at the top and the bottom, which will have sufficiently good low-cycle fatigue performance to allow the turbo-generator and its platform to be displaced through 20 or more cycles of amplitude \pm 5 or 6 times the displacement at initial yielding.

The displacement at yield is given by the formula :

$$
d=9800 a /(2 \pi f)^{2}
$$

Where $d=$ displacement at first yield (mm)

$a=$ induced acceleration at first yield (fraction of $g$ )

$f=$ natural frequency of horizontal vibration of the turbo-generator on its columns (HZ)

Thus:

\begin{tabular}{|c|c|c|}
\hline$f$ & $\begin{array}{l}d \\
\text { Yield } \\
\text { Displacement }\end{array}$ & $\begin{array}{l}\text { Max. Displacement for } \\
\text { defining low-cycle } \\
\text { fatigue performance }\end{array}$ \\
\hline $5 \mathrm{~Hz}$ & $3 \mathrm{~mm}$ & $15 \mathrm{~mm}$ to $20 \mathrm{~mm}$ \\
\hline $3 \mathrm{~Hz}$ & $8 \mathrm{~mm}$ & $40 \mathrm{~mm}$ to $50 \mathrm{~mm}$ \\
\hline
\end{tabular}

To achieve this performance the columns should be designed in accordance with a recognized steelwork code such as the A.I.S.C. Code 1969 which in Section 2.7 page 5-60 defines the limits of flange and web thickness in rolled steel sections necessary. for adequate plastic hinge action.

(b) the end fixings of each column must be capable of withstanding the full plastic moment which the column section is capable of developing in any direction.

(c) the detailing of the column ends must ensure that in the plastic hinge regions there are no notches, holes or other local area reductions which can cause concentration of yielding and premature low-cycle fatigue failure. There must be no welded attachments to columns in plastic hinge areas.

(d) the steel used in the columns must have a well-defined and reasonably uniform yield characteristic.

Appropriate tests on material and inspection of workmanship shall ensure that the specified ductility is. retained after fabricating the welding is completed.

(e) the combined elastic stiffness and as far as possible the combined plastic stiffness of the support columns of a generating unit shall be effective through the centre of mass of the unit in order to minimize torsional vibrations.

(f) all pipework connected to the turbine or generator and all connections to nearby structures of any sort shall be capable of accommodating displacements of the order mentioned in (a) above.

\section{Equipment mounted on $T / G$ Table}

It is desired that all equipment mounted on the $T / G$ table should be capable of withstanding the defined earthquake as amplified by the table with a factor of safety of at least two on its yield strength.

The probable maximum table top accelerations for the different design types mentioned can be summarised thus:

Type of Design

Lowest Frequency of Vibration

Stiff structure Plastic Column Coil springs $20 \%$ damped Coil springs

$10 \%$ damped

Coil springs undamped

\section{Thrust Bearing}

The thrust bearing will be required to transmit to the entire rotating mass of turbine and generator the design accelerations appropriate to the type of support structure chosen and it is desired that they shall be capable of doing so without being damaged. These longitudinal seismic forces will be rapidly reversing at roughly the frequency of the structure and it is desirable that end play in the thrust bearing should be kept to a minimum to avoid increased forces due to shock loading.

\section{Turbine Casing and Generator Stator Fixings}

The same accelerations of the $T / G$ table shall be withstood, without damage by the guide keys, anchor bolts, 
etc. Which secure the Turbine and Generator to the support table.

\section{Condenser}

A condenser solidiy coupled to the turbine exhaust flange would be subject to the same accelerations and manufacturers may find it desirable to mount the condenser on the ground and provide a flexible connection capable of accommodating the amount of displacement appropriate to the support design. (See Ductility in Turbo-Generator supports.)

\section{Main Pipework}

The main pipework (connecting turbine and boilers etc.) will be subject at each termination and intermediate point of restraint, to the random motion of any earthquake modified by the dynamic characteristics of each supporting structure.

Adequate estimation of the likely effects of such shaking requires highly sophisticated analysis methods based on estimated ground motions (supplied by the purchaser). Tenderers shall state whether their pipework analysis methods include facilities for dynamic analysis and if so what would be the cost of such analysis for the most highly. stressed main steam pipework.

Where such analysis is not available or not recommended it will be necessary either to adopt the crude static force approach of the earthquake codes and assume siesmic design forces equal to say, the weight of the components or to provide spring loaded guides and restraints equipped with hydraulic dampers designed to provide up to $30 \%$ or $40 \%$ of critical damping.

Tenderers should note:

(a) that dynamic studies carried out by the purchaser in other fields indicate that a high degree of damping is very effective in reducing earthquake response

(b) that the purchaser has already in one of its steam power stations some hundred of such dampers provided for damping normal vibrations and sees great advantage in their use for earthquake reasons.

\section{Other Pipework}

Other pipework in the station cannot be individually analysed for dynamic behaviour but the following points shall be taken into account in design:

(a) Pipework shall contain no brittle fittings or components unless it can be shown, to the satisfaction of the engineer, that pipework attached to such components either is not inherently strong enough to apply damaging moments or forces or is adequately restrained by suitable supports. Such items would include: cast iron valve bodies, pump bodies, heat exchanger water boxes strainer bodies, etc

(b) The flexibility provided for thermal expansion reasons usually permits large and violent displacement response during earthquakes, and steps must be taken to prevent such lengths of pipe from damaging themsevles or adjacent equipment.

\section{Equipment on Vibration Isolating Mountings}

Flexible mountings for vibration isolation frequently bring the natural vibration frequency of plant items below $10 \mathrm{~Hz}$ giving them a very large acceleration response to earthquakes.

If the special mounting is to prevent vibration from the plant item from shaking its support structure, then excessive response to earthquakes can be prevented by the addition of stops to limit displacement provided -

(a) the stops are made of ductile material

(b) the portions of the plant item that hit the stops are of ductile material

(c) all parts of the plant itern can withstand the shock loading.

If the special mounting is to prevent outside vibration reaching the plant item (for example on instrument panel) then

(2) the stiffness of the mounting should be increased to raise the natural frequency of the plant item to well above $10 \mathrm{~Hz}$ (say $15 \mathrm{~Hz}$ ), (if this does not reduce its effectiveness) or

(b) additional damping must be provided to bring the effective equivalent damping to $30 \%$ or perhaps $40 \%$ of critical (provided this does not unduly reduce the normal isolation effectiveness), or

(c) select plant'items which are shock resistant.

Steam Turbo-Feed Pump

If the low tuned mountings for the turbo feed pump have an "as installed and connected up" natural frequency above ' $10 \mathrm{~Hz}$ they can be regarded as non-amplifiers of earthquake motion and ordinary design procedures using a seismic factor of .33 will be acceptable.

If these mountings are required to have a natural frequency in the 3 to $5 \mathrm{~Hz}$ range then their response to the design earthquake could be between 0.5 and $1.0 \mathrm{~g}$ (depending on the effective damping) unless support columns are designed and detailed to form plastic hinges top and bottom and give a yield point acceleration of about $0.3 \mathrm{~g}$ and maximum acceleration of 0.4 to $0.5 \mathrm{~g}$.

Thrust bearings would need to be designed to withstand accelerations, as indicated, for the chosen support design. It must be noted that these would be rapidly alternating in direction and would be augmented by the presence of end play.

Condensers for this size of turbine would presumably have adequate strength for any of these accelerations even though bolted directly to the turbine exhaust. Cooling water and other pipe connections would have to allow for total earthquake movement of turbine and pump not less than the following:

Design of Natural Response to Displace-Maximum Supports Frequency design Earth-ment at Displacement $\mathrm{Hz}$ quake Yield in design earthquake

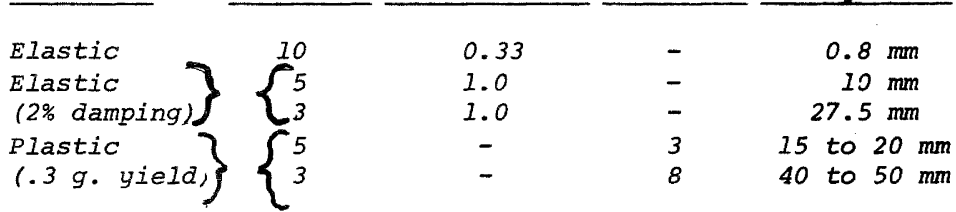

other Parts of the Plant

All parts of the plant not required to be mobile shall be securely fastened in place.

Seismic force (Fs) for the design of miscellaneous plant items and their fixings shall be not less than those given below provided that no stress calculated from the action of the seismic force shall be reduced by considering the downward action of more than half of the deadweight.

The values of $C s$ in the equation - 


$$
\begin{aligned}
F s=C S \times W S \text { where } F s & =\text { Seismic Force } \\
C S & =\text { Seismic Force Factor } \\
\text { Ws } & =\text { Weight of part or item }
\end{aligned}
$$

shall be -

(a) for plant items robustly constructed from ductile materials and mounted on firm foundations near ground level:

- Cs not less than 0.33

Examples Fans, pumps, motors, control panels, or cubicles, batteries, transformers; switchgear, tanks, receivers, containers.

(b) for plant items mounted on or near ground level on elevated or otherwise slightly flexible supports having a natural frequency of vibration of less than $10 \mathrm{~Hz}$ :

- if the support structure and/or the plant item is thoroughly detailed for ductility and ductile yield does not cause failure to function or damage to adjacent or connected equipment

- Cs not less than 0.33

Examples = Tall tanks or containers supported on narrow base or foundation, feed heaters, transformers or other heavy items supported on raised plinths or stands.

- if the plant item or its support structure would fail under earthquake loading in a brittle or non-ductile manner then $C s$ shall be as read from drawing number $z 5590$ (Fig. 10) for the appropriate natural period and damping. In addition the design shall provide an ultimate fracture strength or crippling strength of not less than three times the seismic loading.

Examples - items with critical components made of glass, porcelain, unreinforced ceramics, non-ductile cast iron or cast aluminium

- items with strain concentrating notches in plastic hinge areas e.g. threaded pipe joints

- braced support structure not fully cross-braced i.e. having single braces which would fail in compression.

(c) for equipment mounted on or coupled to the turbogenerator support slab, care shall be taken to ensure that the plant item as installed, has no natural frequency of vibration close to those of the turbogenerator slab and which are below about $10 \mathrm{~Hz}$ - if this condition is met Cs shall correspond to the momentary maximum accelerations estimated for the particular design of $T / G$ support structure (clause "Special Requirements").

Examples - Fans, motors, pumps, switchgear, control panels, tanks, pipework."

\subsection{Part of N.Z.E.D. Specification for 250 MW Steam Raising Units}

\section{"EARTHQUAKE DESIGN}

\section{Site Earthquake Condition}

The site is subject to seismic disturbances and all parts of the plant essential to safe and satisfactory operation shall be designed and installed to have a substantial degree of resistance to the violent and irregular shaking to which they may be subjected in earthquakes.
Design Capability

\section{Tenderers shall confirm}

a) that they have or are prepared to engage, structural designers who are thoroughily familiar with modern earthquake design codes for ordinary buildings and with their adaptation to boiler support structures.

b) that their steam raising unit designers clearly understand the nature of the dynamic response of their equipment and its parts, to the random motion of earthquakes as transmitted and modified by the support structure.

c) that all their designers understand the vital role in establishing real resistance to earthquakes, played by "adequate ductility" and "freedom from low-cycle fatigue", and that they are aware of disastrous consequences of inadequacy in these respects demonstrated by the poor performance of several types of structure and equipment, in recent earthquakes, in particular the San Fernando earthquake of February 1971.

\section{Earthquake Experience}

Tenderers shall state whether any plant and equipment similar to that offered has been subjected to any severe earthquake - if so what was its size and distance to the epicentre, what damage was caused and what design lessons were learned.

\section{Earthquake Design Code}

Seismic design of the main steam raising units and their support structures shall be based on New Zealand Standard Building Bylaw "BasiC Design Loads" N.Z.S.S. 1900: Chapt. 8 (1965) and Amendments No. 1, 2 and 3 and on "Commentary on Chapter 8 of N.Z.S.S. 1900" MP12 (1965) and its amendments - insofar as these two documents are applicable.

\section{Design Procedure}

The total lateral force $V=K_{A} C$ Wt shall be distributed over the height of the structure in accordance with the so-called"triangular distribution" specified in clause 8.36 .3 .1 or 8.36 .3 .2 , in order to determine shear loads, overturning moments and individual member loads.

In determining the total horizontal seismic force $V=K_{A} C \mathrm{Wt}$, in accordance with clauses 8.36.1.1 or 8.36.1.2 for designing the steam raising units and their support structures, the value of $C$ shall be taken as .167 . $C$ shall not depend on the natural period of the structure because the ground response spectra at the Huntly site are believed to have peak values in the range of periods which are likely to occur in boiler structures of this size.

The value of $K_{A}$ (normally taken from table 5A) shall be taken from Table I of this document.

\section{Special Seismic Factors}

For the "moment resisting space frame" design the lower seismic coefficient $\left(K_{A} C=.15\right)$ reflects the better authenticated earthquake resistance of this type of design provided adequate attention is given to design detail and quality control of materials, manufacture and installation.

The higher seismic coefficient $\left(K_{A} C=.2\right)$ is specified for the braced design because of the greater uncertainty of providing energy absorbtion through plastic yielding and the less well authenticated energy absorbtion of high tensile bolted joints.

If a braced design is offered each braced panel shall 
be fully cross braced - so that the crippling of a member in compression does not remove all the bracing effect from that panel. An exception would be a panel in which bracing members in compression do not fail even when all other panels in the structure have reached their maximum post-yield strength.

\section{Steelwork Design}

Member sizes and connection details shall be carefully chosen to provide satisfactory ductile and low cycle fatigue performance capable of surviving repeated alternating deflections up to several times those corresponding to first yield.

Tenderers shall use a recognised steelwork design code which covers adequately not only the plastic properties of steel sections necessary for ultimate strength design, but in addition the plastic hinge properties necessary for earthquake resistance in "ductile moment resisting space frames". The "Steel Construetion Manual $1969^{\circ}$ and related publications of the American Institute of Steel Construction would be appropriate.

\section{Over Strength}

Tenders shall include preliminary estimates of :

a) the maximum acceleration experienced at the top of the structure when vibrating in its first mode at an amplitude which would cause stresses to reach yield point

b) the natural frequency of the first mode of vibration

c) the probable maximum acceleration of the top of the structure corresponding to the fully yielded condition of the structure.

Note: . This information is required for each major axis of the structure.

- these estimates may be based on a "straight line" mode shape if more sophisticated methods are not available at this stage.

- the "probable actual" yield stresses of the proposed steel shall be used not the "specified minimum". . foundation flexibility need not be taken into account at this stage.

. for braced structures the maximum acceleration would correspond to structure forces when bracings in compression are at their crippling load

- this information is required to indicate the extent of over strength effects on the upper portions of the plant in minor earthquakes (i.e. at first yield) and in larger earthauakes.

Tenderers shall state what type of steel they intend to use and what experience they have had in using it for earthquake resistant designs.

\section{Foundation Loads}

Foundation loads shall be calculated for normal loads and also for the combination of normal loads with those earthquake loads (larger than the basic design loads) which correspond to full yielding. These shall be stated separately for each direction in each major axis of the structure.

The successful tenderer shall check these estimated values and shall check whether the completed installation has significant vibration modes below about $10 \mathrm{~Hz}$ and whether these require any alteration in the design.

Seismic design factors for miscellaneous plant items and equipment and special points to be noted in earthquake design are set out below.

\section{Earthquake Response Spectra}

The foregoing rules present a pseudo-dynamic approach to earthquake resistance. Assistance on doubtful points may be sought from the single body response spectra which have been estimated from preliminary site investigations and are shown on drawing Z 5590 (Fig. 10).

\section{Vertical Component}

This drawing includes an estimate for the vertical component of earth shaking and although this does not usually present problems, tenderers shall consider whether their normal practice in providing vertical support for furnace walls, steam drums, etc. would provide adequate margins of ductile behaviour in the presence of a vertical component of the size and nature suggested by this estimate.

\section{Seismic Design Factors for Portions of Structure and Miscellaneous Plant and Equipment}

The following requirements are applicable to items of plant and equipment not in the category of "building structures", whether mounted on their own foundations at or below ground level or supported as accessories on a major structure provided for another purpose.

- also to portions of the plant dynamically part of a major structure, but where fixings to the structure must be given special attention (e.g. steam drum, furnace wall, tube banks of the steam raising equipment).

These requirements are derived from Table $5 B$ under the provisions of clause 8.36.1.6 of N.Z.S. 1900 chapt. 8: 1965 by making more detailed allowance for the following factors:

- height above ground at which equipment is mounted in support structure

- degree of rigiaity or flexibility in the equipment or its supports

- degree of ductility which is available or is acceptable in the equipment or its supports

- degree of damping which exists or is introduced into the equipment or its supports.

\section{Design Procedure}

Seismic forces for the design of parts or portions of the main structure including miscellaneous plant items and their supports and fixings shall be determined from the following formulae (which are adaptations of clauses $8.35 .1,8.36 .2 .1$ and 8.36 .3 .1 ) :-

\section{$\underline{F_{S}=K_{B} C W_{S}}$ or $\underline{f}_{X}=K_{X} C W_{X}$ WHICHEVER IS THE GREATER}

and $K_{B}$ and $K_{X}$ shall be not less than given in Table II.

Where a "working stress" design procedure is used these loads shall be combined with normal and other appropriate loads (except wind) and used in conjunction with appropriate "working stresses" to determine sizes.

Where an ultimate strength design procedure is used appropriate load factors shall be applied to these loads before combining them with other factored loads to determine the required ultimate strengths. 
three on ultimate strength shall be provided.

For fastenings and supports of equipment fastened by its base, calculated forces resisting overturning shall not be reduced by the counter action of any more than half of the deadweight of the equipment concerned.

\section{Definition of Symbols}

$F_{S}$ or $F_{x}$ - Horizontal seismic design force

$w_{S}$ or $w_{x}$ - Weight of portion or plant item

C - Basic seismic coefficient $=0.167$ for power stations unless otherwise stated.

$K_{B}$ - Seismic force factor for item with weight $W_{S}$, mounted at ground level or in lower part of structure (as Table $5 B$ unless otherwise specified in Table II hereof)

$K_{x}$ - Seismic force factor for item with weight $W_{x}$, mounted in upper part of structure (as implied by clause 8.35 .1 and 8.36 .3 .1 unless otherwise specified in Table II hereof).

$K_{A}$ - Seismic force factor related to type of structure (as Table 5A unless otherwise specified in Table I hereof).

$h_{x}$ - height above ground or base of structure at which item with weight $w_{x}$ is mounted.

$h_{c g}$ - height above ground or base of structure at which centre of gravity of structure with total Weight $w_{t}$, is located.

NOTE: From formulae in clauses 8.36.3.1, 8.36.1.1,

$$
f_{x}=V \cdot W_{x} \cdot h x / \sum W_{x} h_{x} \text {, and } V-K_{A} C w_{t}
$$

and noting that $\sum W_{x}{ }_{x} / W_{t}=h_{C g}$ it is evident that $E_{x}=k_{A} \cdot\left[h_{x} / h_{C g}\right] . C \cdot W_{x}$ Thus $k_{x}=\left[h_{x} / h_{C g}\right] K_{A}$ for the basic case in Table II namely "Rigid Item Rigidly Mounted".

\section{Categories of Structure Portions and Plant Items}

"Rigid item rigidly mounted" - An item which together with its mounting is so rigidly coupled to its foundation or to the main structure that it has no mode of vibration with a frequency less than 10 cycles/second.

"Flexible item or ilexibly mounted item". - An item where its own flexibility or that of its mounting or of the combination gives a mode of vibration with a frequency less than 10 cycles/second.

"Ductile Item" - A plant item which by its own ductility or that of its support or fixings is able to accept repeated deflection beyond yield point without significant impairment of its safety or its ability to function, and without damage to other items connected to it or adjacent to it.

"Limited Ductility Item" - Much equipment and many structures constructed of non-brittle material by ordinary design methods may not be specifically detailed for ductility, but may nevertheless be assumed to have considerable earthquake resistance.

"Non-ductile Item" - A plant item and its supports or fixings, in which failure load is determined: - by the brittle characteristics of the material of which is constructed or

- by its dependance on precisely machined dimensions for its continued functioning or - by "crippling" of a compression member and is therefore not able to accept repeated deflections beyond yield point.

An item which in normal operation is highly stressed may fall in this category if yielding under earthquake loading results in poor low cycle fatigue performance because of the combined stressing and yielding.

\section{SPECIAL POINTS IN EARTHQUAKE DESIGN}

Steam Raising Units

The boiler drums, headers, waterwalls and roofs of furnaces, tube banks which are supported with due allowance for thermal expansion shall also be restrained in each horizontal direction so that they will follow the earthquake induced movements of the main structure with a minimum of backlash.

The required guides and restraints shall be designed using factors chosen from Table II in accordance with the appropriate stiffnesses and ductilities which can be built into them. It is likely that class IIR or IIF would be appropriate. Note that these depend on the type of structure and the height of its centre of gravity.

\section{Main Pipework}

Main pipework (connecting turbine, boiler, etc.) will be subject at each termination and intermediate point of restraint, to the random motion of any earthquake modified by the dynamic characteristics of each supporting structure.

Adequate estimation of the likely effects of such shaking requires highly sophisticated analysis methods based on estimated ground motions (supplied by the purchaser). Tenderers shall state whether their pipework analysis methods include facilities for dynamic analysis and if so what would be the cost of such analysis for the most highly stressed main steam pipework.

Where such analysis is not available or not recommended, it will be necessary either to adopt the crude static force approach of the earthquake codes and assume seismic design forces equal to, say, the weight of the components or to provide spring loaded guides and restraints equipped with hydraulic dampers designed to provide up to $30 \%$ or $40 \%$ of critical damping.

Tenderers should note:

1) that dynamic studies carried out by the Department in other fields indicate that a high degree of damping is very effective in reducing earthquake response

2) that the Department has already in one of its steam power stations some hundreds of such dampers provided for damping normal vibration and sees great advantage in their use for earthquake reasons.

\section{Gas and Oil Pipework}

All pipework carrying gas or oil shall be carefully detailed to ensure that

- there are no brittle fittings, valves or equipment bodies which are not capable of developing the full beriling strength of the pipe or are not protected from being subjected to such bending.

- movement of the soil outside the foundations cannot cause fractures to oil or gas pipework inside the building. 


\section{General Pipework}

other pipework in the station cannot be individually analysed for dynamic behaviour, but the following points shall be taken into account in design:-

\section{1) Pipework shall contair no brittle fittings or com-} ponents

2) the flexibility provided for thermal expansion reasons usually permits laxge and violent displacement response during earthquakes and steps must be taken to prevent such lengths of pipe from damaging themselves or adjacent equipment.

\section{Equipment on Vibration Isolating Mountings}

Flexible mountings for vibration isolation frequently bring the natural vibration frequency of plant items below $10 \mathrm{~Hz}$ giving them a very large acceleration response to earthquakes.

If the special mounting is to prevent vibration from the plant item from shaking its support structure then excessive response to earthquakes can be prevented by the addition of stops to limit displacement provided -

the stops are made of ductile material

the portions of the plant item that hit the stops are of ductile material

all parts of the plant item can withstand the shock loading.

If the special mounting is to prevent outside vibration reaching the plant item (for example an instrument panel) then

a) the stiffness of the mounting should be increased to raise the natural frequency of the plant item to well above $10 \mathrm{~Hz}$ (say $15 \mathrm{~Hz}$ ) (if this does not reduce its effectiveness) or

b) additional damping must be provided to bring the effective equivalent damping to $30 \%$ or perhaps $40 \%$ of critical. (provided this does not unduly reduce the normal isolation effectiveness) or

c) select plant items which are shock resistant.

\section{Axial Loads in Rotating Machinery}

Tenderers shall note that earthquake motion can cause very high shock loadings where horizontal shaft rotating machines have endplay of the order of 10 to $20 \mathrm{~mm}$. Plant supported on flexible structures would be particularly susceptable. Tenders shall include comment on this point in respect to major plant items e.g. fans and motors."

\section{INTELLECTUAL OBSTACLES IN SEISMIC DESIGN}

In its endeavours to have earthquake effects recognised as dynamic phenomena, the Department has encountered many problems both practical and intellectual of which some have proved almost as difficult as trying to change a person's religion. Some of these are :-

\section{1 "Earthquakes are for Civil Engineers"}

This view is remarkably widespread and it is only in recent years that the mounting toll of earthquake damage to electrical and other plant and equipment has begun to reveal the fallacy.

Novoa 1970 (14) and Beutler 1970 (15) in Chile along with Brown Boveri 1970 (15) in Switzerland were some of the earliest to bring adequate theoretical understanding of earthquake effects on electrical equipment.

The Japanese Electrical Industry, though a little later starting have, with their typical thoroughness, devoted immense resources to research and development. The major manufacturers have equipped themselves with electrohydraulic shaking tables capable of applying earthquake type motion to full size equipment. Japanese manufacturers (16) (17) for example, describe the detailed and thorough development and testing which went into their $500 \mathrm{kV}$ circuit breakers and their SF 6 insulated metalclad switchgear. Their Telecommunications industry has carried out extensive studies such as (18) and very detailed work has been done on steam boilers (19) (20) (21).

The safety requirements for the electrical equipment of nuclear reactors have brought the jmmense research resources of the American electrical industry onto earthquake effects on electrical equipment. One manufacturer (23) describes the high amplification of earthquake motion in plant mounted high in buildings and give details of proof tests using "sine beat" pulses. Others $(24,25)$ describe other methods of testing for earthquake resistance.

The disastrous consequences of the Sar Fernando 9 February 1971 earthquake have stimulated the interest of the electrical industry still further.

The author believes that in New Zealand the teaching about earthquakes is confined mainly to civil engineers.

\section{2 "f = m.a What's so difficult about that?"}

As a consequence of the above-mentioned fallacy, a great many people see that "there is no difficulty about earthquake design" so they take the acceleration that the civil engineers use, apply it to their structure or equipment, uniformly all over, and confidently assure you "we design for earthquakes". The disastrous outcome of such design methods in the San Fernando earthquake has yet to become widely known amongst those for whom earthquakes are still civil engineering matters. The history of engineering technology shows that it often takes several disasters to alter a widely held view.

The equation $f=m . a$. is, of course, used to write the differential equation of motion of a flexibly mounted mass subjected to earthquake motion.

Force acting on mass at any instant $=$ mass $\mathrm{x}$ absolute acceleration = force due to damping effect + force due to spring deflection i.e. $m(\ddot{x}+\ddot{y})=-C \dot{x}-k x$

where $\ddot{x}=$ acceleration of the mass with respect to the ground

$\dot{x}=$ velocity of the mass with respect to the ground

$\mathrm{x}=$ displacement of the mass with respect to the ground

$\ddot{y}$ = acceleration of the ground

$\ddot{x}+\ddot{y}=$ absolute acceleration of the mass

$C$ = damping constant (multiplied by velocity gives damping force) 


\section{$\mathrm{k}$ = spring constant (multiplied by displacement gives spring force)}

(minus signs come from definitions of positive directions

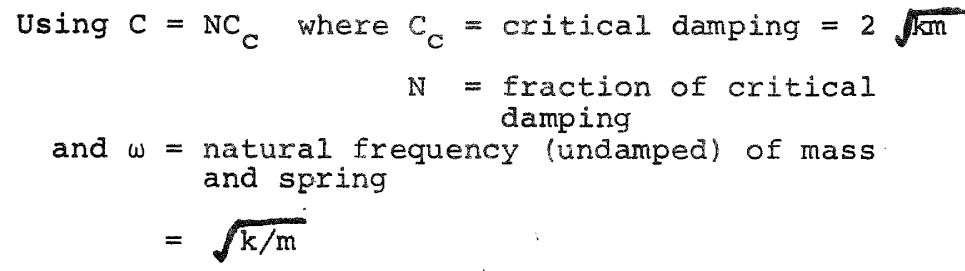

the equation can be rewritten $\ddot{x}+2 N \omega \dot{x}+\omega^{2} x=-\ddot{y}$ If $\ddot{y}$ is the time history of the ground acceleration of an earthquake the equation can be solved by computer to find either the time history of $\ddot{x}$, $\dot{x}$ and $x$ or to find their maximum value which gives maximum load on the spring supporting the mass.

Complex structures, represented by multiple masses, springs and dampers require a differential equation for each mass. These are expressed most conveniently by matrix methods and can be solved simultaneously by computer.

A thorough familiarity with these principles and their development in structural mechanics is essential to any real understanding of earthquake problems. A useful introduction is Biggs (26).

\section{3 "Let $f$ be the earthquake frequency ...."}

This marks the approach of the experienced mechanical engineer trying to apply his knowledge of sinusoidal vibration to earthquake design without comprehending the difference between the narrow peaked response spectra for sine waveexcitation and broad, irregular peaked response spectra for earthquakes. One of the world's largest manufacturers presented a paper at one of the world's largest conferences on earthquake protection for one of the world's most expensive plants, and the recommendations were technically invalid. The author hopes this idea has not been used.

\section{4 "Get the manufacturer to advise"}

In many fields especially in electrical engineering, purchasers of plant can place great reliance on advice given by manufacturers because of the great resources in experience and research which lie behind it.

In earthquake engineering, it has been a long struggle to get manufacturers to present even quite elementary calculations of earthquake resistance. This is why the Department's specifications have until recently had only the most elementary earthquake requirements.

Now, fortunately, as a result of the increasing number of reports of seismic damage and of the increasing number of purchasers requiring high earthquake resistance in their equipment the sophistication of manufacturer!'s methods has increased substantially. As a result, more sophisticated clauses have been added to the switchgear specification and more items have been defined in terms of natural frequency of vibration which of course assumes that there is a familiarity with structural dynamics. of understanding of earthquake response at which they can effectively administer earthquake clauses is a considerable undertaking still not completed.

\subsection{Factors of Safety}

Perhaps the most universal obstacle to understanding a seismic design is the concept of Factor of safety. This is, of course, a fundamental part of a great many design philosophies - a "design load" or "design condition" is assessed and a "design stress" is used to determine "size" or other "property" of the structure or object. In addition, steps are usually taken to ensure that the "design load" or "condition" are not exceeded.

Electrical engineers, for example, have an arsenal of protective measures, ranging from fuses, surge diverters and circuit breakers to sophisticated protective relays which ensure complete removal from service of any part of the system which has been taken beyond its design conditions.

Mechanical engineers often use very large factors of safety or resort to safety valves, fusible plugs, shear pins, torque limiters, break-links, overspeed trips, and even control systems to control the maximum "load" applied.

Civil and structural engineers are brought up on Factors of Safety and even in "plastic" or "Ultimate Strength" design, design loads are "multiplied by a factor" instead of stresses being "divided by a factor."

Thus it is not at all surprising that the basic concept of designing for ductility to achieve resistance to earthquakes is not well understood outside a limited circle of earthquake engineering experts.

It is still not uncommon for a civil engineer to refer to the spectrum-like graph which defines the basis seismic coefficient namely Fig. 1 of NZSS 1900: Chapt.8, as "the earthquake for which we are designing!". This is erroneous in two ways

- SANZ MP12: Commentary on Chapter 8 makes it clear that Chapter 8 is intended to make provision for earthquake ground motions in the range 0.25 to $0.4 \mathrm{~g}$ (approximately M.M.9).

- A "design spectrum" such as Fig. 1 is not a response spectrum defining an earthquake motion - it is what is left of a set of response spectra after being severely reduced in anticipation of ductile properties assumed to be in every structure.

This involves the concept of a structure "working" well beyond its yield point not just once, but a number of times. This is a revolutionary thought for a "factor of safety" trained man and even when accepted, is not easy to apply. It requires familiarity with the works such as Jennings and Husid, Bertero and Popov on the behaviour of yielding structures mentioned in section 3.3 and the interesting quantitative assessment of yield damage by Kasiraj and Yao (27).

\section{CONCLUSION}

This paper has reported N.Z.E.D. involvement 
in earthquake resistant design over the last four years and implied that in a small way it has made some contribution to the art. It has outlined the enormous growth of research and development in all parts of the field, especially the electrical sector under the joint pressures of nuclear safety requirements and earthquake damage to major electrical plant.

It has indicated the wide range of earthquake problems encountered in electric power system work and the very different examples quoted emphasise that there can be no comprehensive specification covering all equipment - unless it be of library proportions.

Some of the difficulties encountered have been described, but the greatest is perhaps best summed up by Professor P. C. Jenning's remark at a meeting of the N.Z. Society for Earthquake Engineering - "Codes are for nonengineered structures". This is delightfully provocative, but if you take his point correctly you will add " - because you just can't afford to engineer from first principles your bread and butter design work".

This is a point of great importance to electrical and mechanical engineers seeking guidance on earthquake resistance for their peculiar kinds of structure - no matter how experienced a civil engineer may be in applying earthquake codes, if he has not acquired a thorough understanding of the theory of dynamic response of structures to earthquakes, he is probably not only quite unable to give advice on special plant and equipment, but may even be quite misleading.

Thus, electrical and mechanical engineers must master the underlying principles in order to be in control of their earthquake problems, but they also must draw up simple rules or codes so that "bread and butter" design work can be carried out quickly and soundly without the involved processes of going back to first principles.

All such codes are approximations, and no code can cover all cases. Behind every code, watching that it is not improperly applied, watching that it does not get out of date, ready to give advice in doubtful cases, and to rewrite or extend the code for special cases, must be engineers with an adequate body of technical know-how, continually keeping up to date at a technical level that is high enough to be able to look ahead and identify difficult areas before they become problem areas. This is a primary function of the professional engineer and one which cannot be passed on to anyone else.

It could be true that the discredit which Leeds in ref (2) suggests has fallen on the response spectrum methods of design, is in large measure due to the "efficiency" of the industry in having produced a design procedure which can be applied without understanding the reasons behind it.

Efficiency experts and productivity promotors will recognise that such design procedures save time and money and allow work to be done with less technical skill, but they must also recognise that the application of these "nonengineered" methods to larger and larger projects without high level supervision is a sure way of treading the all too familiar stepping stones to progress - one disaster after another.

It is clear, however, that the response spectrum method, with proper recognition of the part played by ductility requirements and preferably with guidance from someone who has actually carried out non-linear time history analyses, still has a most important part to play in the earthquake engineering of the more numerous, less spectacular structures which come in the medium height, short period range.

The author offers thanks to the management of N.Z.E.D. for having allowed him the opportunity of working in depth in this field and to the various colleagues and friends within and outside the Department who haveassisted in various ways - and to his wife, who is heartily sick of earthquake talk and earthquake papers, but who has nobly put up with it all.

\section{REFERENCES}

1. Hitchcock, H. C. (1969) "Electrical Equipment and Earthquakes", N.Z. Engineering 24 (1) 3-14.

2. Leeds, D. J. (1972) Report on Conference on 1971 San Fernando, Ca., Earthquake Civil Engineering ASCE May 1972

3. Agbabian-Jacobsen Associates (1971) Report for Bonneville power Administration "Assessment of Earthquake Resistant Design of AC-DC Converter Stations (H.V.D.C. Pacific Intertie)" .

4. Limseth L. and Skoglund B. (1969) "Mechanical Dimensioning of Supporting Insulators for Earthquake Cantilever Loading". I.E.E.E. Conference paper No. 69CP676 - PWR.

5. Winthrop D.A. and Hitchcock H.C. (1971) "Earthquake Design of Structures with Brittle Members and Heavy Artificial Damping by the Method of Direct Integration" Bull. N.Z. Soc. Earthquake Engineering. Vol. 4 (2) Apr. 1971.

6. Kelly, J.M., Skinner, R.I., Heine, A.J. (1972) "Mechanisms of Energy Absorbtion in Special Devices for use in Earthquake Resistant Structures" - Bull. N.Z. Society for Earthquake Engineering, Vol. 5, No. 3 Sept. 1972.

7. Gilmour, R. M. and Hitchcock H. C. (1971) "Use of Yield Ratio Response Spectra to Design Yielding Members for Improving Earthquake Resistance of Brittle Structure" Bull. N.Z. Society for Earthquake Engineering, Vol. 4, No. 2, April, 1971.

8. Jennings, P.C. (1965) "Earthquake Response of a Yielding Structure", Journal of Eng. Mech. Div. ASCE EM4 Aug. 1965.

9. Jennings P.C. and Husid R. (1968) "Collapse of Yielding Structures during Earthquakes" $\mathrm{J}$. of Eng. Mech. Div. ASCE EM5 Oct. 1968.

10. Bertero V.V. and Popov E.P. (1965) "Effect of Large Alternating Strains on Steel Beams" J. Struct. Div. ASCE STl Feb. 1965.

11. McKenzie D. J. (1969) "The Behaviour of Lifts - Wellington Earthquake 1 Nov. 1968" Bull. N.z. Society for Earthquake Engineering, Vol. 2, No. 31969.

12. News Item. Engineering News Record 17 Feb. 1972 p.13. Report by J. M. Ayres on damage to elevators on 9 Feb. 1971 "100 failed by snarled cables, 174 because generators knocked out, 674 because counterweight 
jumped rails".

13. Ayres J.M. (1971) Report on Non-Structural Damage in 1964 Alaska Earthquake "The American Plumbing Engineer" (Building Systems Design) Oct. Nov. Dec. 1971.

14. Novoa F. (1970) "Earthquakes and Substation Equipment - Arrangement and Specification". Paper 23-02 C.I.G.R.E. 1970.

15. Cuk, N. and Ramseir, E. (1970) "High Voltage Switchgear for Earthquake Prone Areas" Brown Boverie Review 121970.

16. Oishi M. (1973) $500 \mathrm{kV}$ Substation Equipment in Conformity to Environmental Conditions. Toshiba Review Jan. 1973.

17. Ushio T. et al (1972) "Security of Seismic Construction of High Voltage Switchgear IEEE Trans PAS-91 (6) Dec. 1972.

18. Yoneo S. (1972) Vibration tests on Telecommunications equipment Japan Telecommunications Review Oct. 1972.

19. Shiraki K. and Nakazawa S. (1967) "Study on the Design of Boiler and Boiler Girder to Resist Earthquake - Simple Models" Mitsubishi Heavy Industries, Technical Review Jan. 1967.

20. Otaka K., Nakamura T. Irie Y. (1968) "Study on Earthquake Design of Boiler and Girder - Internal Elements" M.H.I. Tech.
Rev. May 1968.

21. Shiraki K., Nakazawa, S. (1968) "Study on Aseismic Design of Boilers and Structural Steels" M.H.I. Tech. Rev. Sept. 1968.

22. Fischer E.G., Fergusson W. H., Colaiaco A.P., (1972) "Test Method to Demonstrate Seismic Capabijities of Equipment". IEEE PAS-91 (5) 1972.

23. Colaiaco A.P., Albert W.S. (1972) Seismic Testing of Metal Clad and Metal Enclosed Switchgear using sine Beat Vibrations. IEEE PAS-91 (5) 1972

24. Gallant C. R. and others (1971) "Testing Program for Qualification of Switchgear Subjected to Earthquake" IEEE PAS-90 (1) 1971 .

25. von Damm C.A. Seismic Testing for Reliable Instrumentation and Control systems IEEE PAS 921973.

26. Biggs John M. (1964) "Introduction to Structural Dynamics" McGraw-Hill.

27. Kasiraj I. and Yao J.T.P. (1969) "Fatigue Damage in Seismic Structures" J. Struct. Div. ASCE. ST8 Aug. 1969.

2.8. Skinner, R.I. (1964) D.S.I.R. Bulletin 166: Earthquake-Generated Forces and Moments in Tall Buildings, N.Z. Government Printer.

TABLE 1.

VALUES OF $K_{A}$

(additional items for Table 5A of N.z.S.S. 1900: Chapt.8)

for a ductile moment resisting space frame without diagonal bracings

for a fully cross braced type of structure

$\mathrm{K}_{\mathrm{A}}=0.9$

$\mathrm{K}_{\mathrm{A}}=1.2$

(Note: The effective seismic coefficient

$\mathrm{K}_{\mathrm{A}} \mathrm{C}$ is therefore $0.9 \times .167=0.15$

or $1.2 \times .167=0.2$ ) 


\section{TABLE II.}

VALUES OF $K_{B}$ AND $K_{x}$

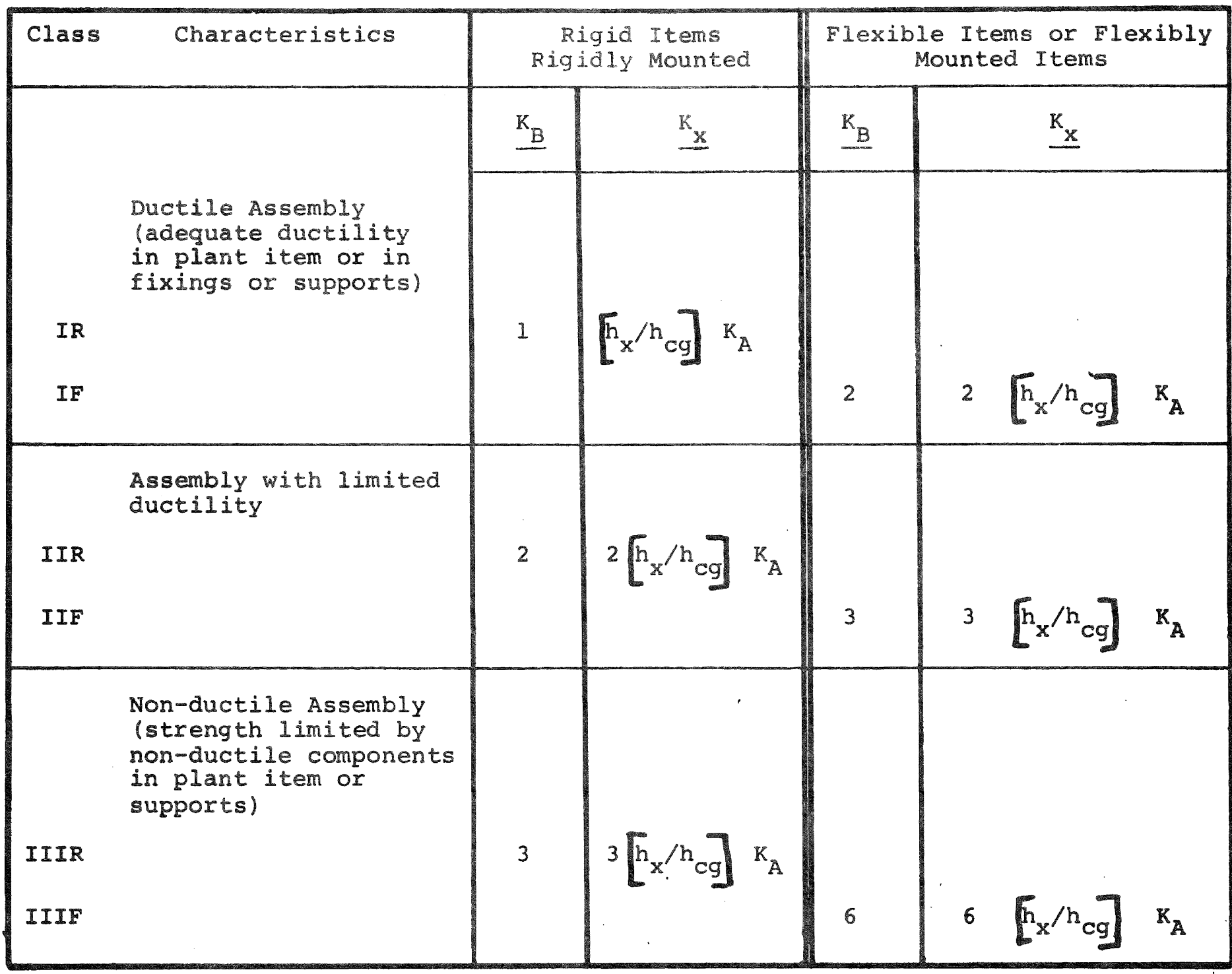

NOTE: Alternatively for Class III items, dynamic analysis methods may be used to estimate the likely response of equipment to earthquake motion of the size and nature implied by the response spectra on drawing $z$ 5590. (Fig. 10) 


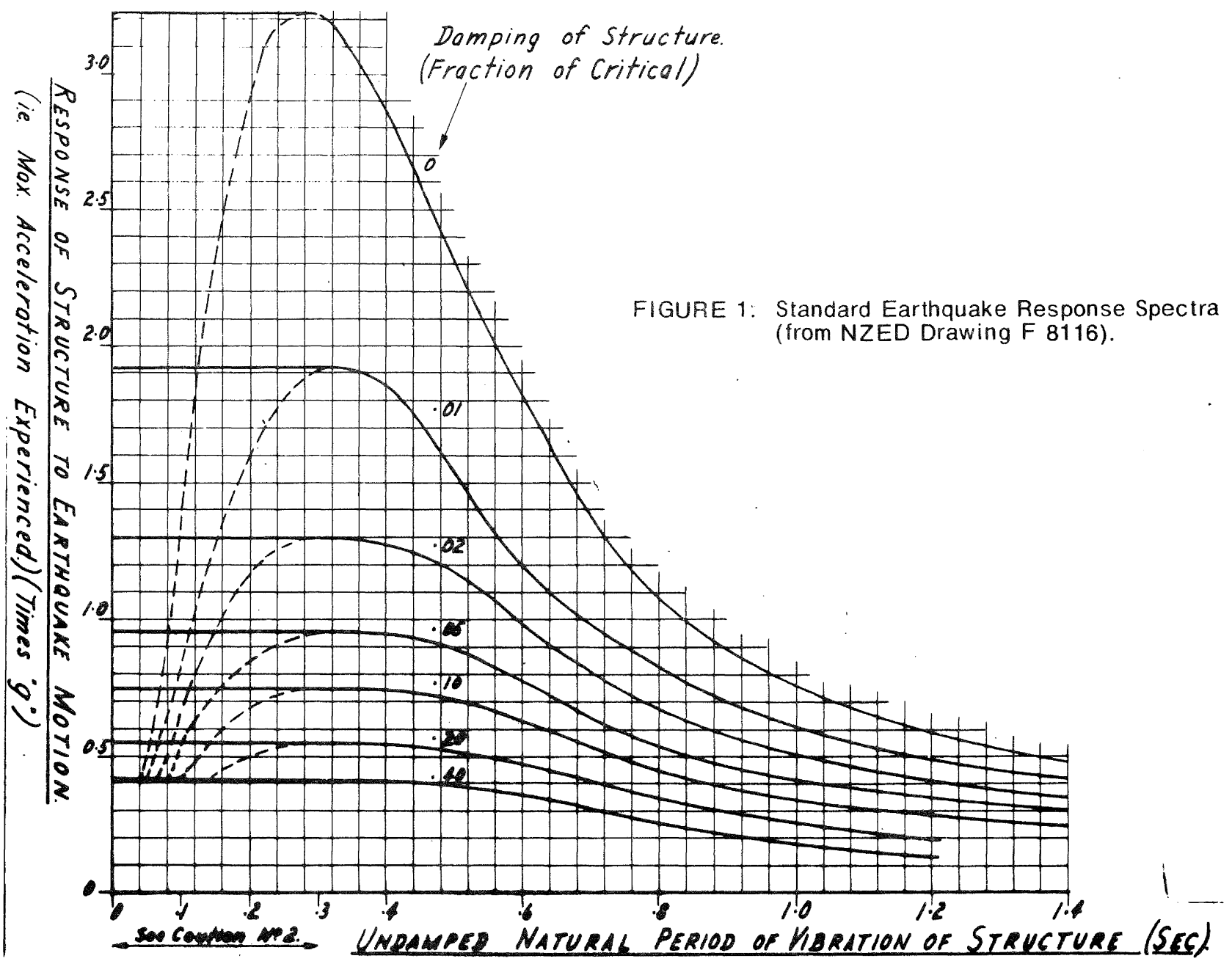

EXPLANATORY NOTES FOR STANDARD EARTH.ZUAKE RESPONSE SPECTRA:-

(1) These rosponse spectrum curves define for design purposes a "standard" eurthquake which could occur at any given site bout once in hundred years in many parts of $N$. 2 . less frequently in others.

(2) They define the effects wich could be expected at a place situated on deep firm allurium about l2 miles from the epicentre of a shallow (1.e. 15 miles deep) earthquake of Richter magnitude $6 \frac{3}{4}$. (This magnitude can be expected to occur within 70 miles of Wellington about once in 15 years on the average.)

(3) For sites on firm rock and/or nearer to an epicentre spectrum curves would be similar in shape but would peak at lower natural period value, say . 15 to .25 sec.

(4) For sites on poor foundations and/or at greater distances from larger earthquakes the spectrum curves could peak at higher natural period values - higher than 1 second in certain conditions.

(5) These pectra are derived from those given in Fig. 15 of the D.S.I.R. Bulletin 166 - "Earthquakegenerated Forces and Movements in Tall Buildings" - R. I. Skinner (1964). The spectra in Fig. 15 are recomended so the basis for the earthquake design of tall buildings and also were the starting point for deriving the selsmic design factors recommended in N.7.S.S. 1900! Model Bullding Bylaws: Chapter 8. Basic Design Loads - which apply to Power station and Substation buildings.

(6) The response spectrum curves in Fig. 15 were in the absence of N.?. .data, derived from the strong motion records of four United States earthquakes, Elcentro (Calif.) 1934 and 1940; 0lympla (Wash.) 1949; and Taft (Calif.) 1952. Taking both horizontal components of each, the eight records were "weighted" to the same size, applied by analogue computer to the electrical equivalent of the model shown and the average response determined for each value of natural frequency and damping.

Caution: (1) The smoothness of the curves does not imply corresponding accuracy. Mr. Skinner suggests that bout $90 \%$ of earthquakes of similar size would cause a response within $30 \%$ of the plotted values.

Caution: (2) For structures with natural periods in the range $0-.3$ seconds where the curves are dotted, the peak value for the curve (i.e. the horizontal atraight line) should be used instead, unless it is quite certain that unexpected flexihility in supporti andor foundations wil not increase their period and that local ground conditions do not shift the location of the peak to a lower period.

Caution: (3) The curves do not define a miaimum earthquake - larper can occur but less frequently. Statistical data on this point will be scarce for the next 2 or 3 hundred years, by which time more adequate data may be available. 


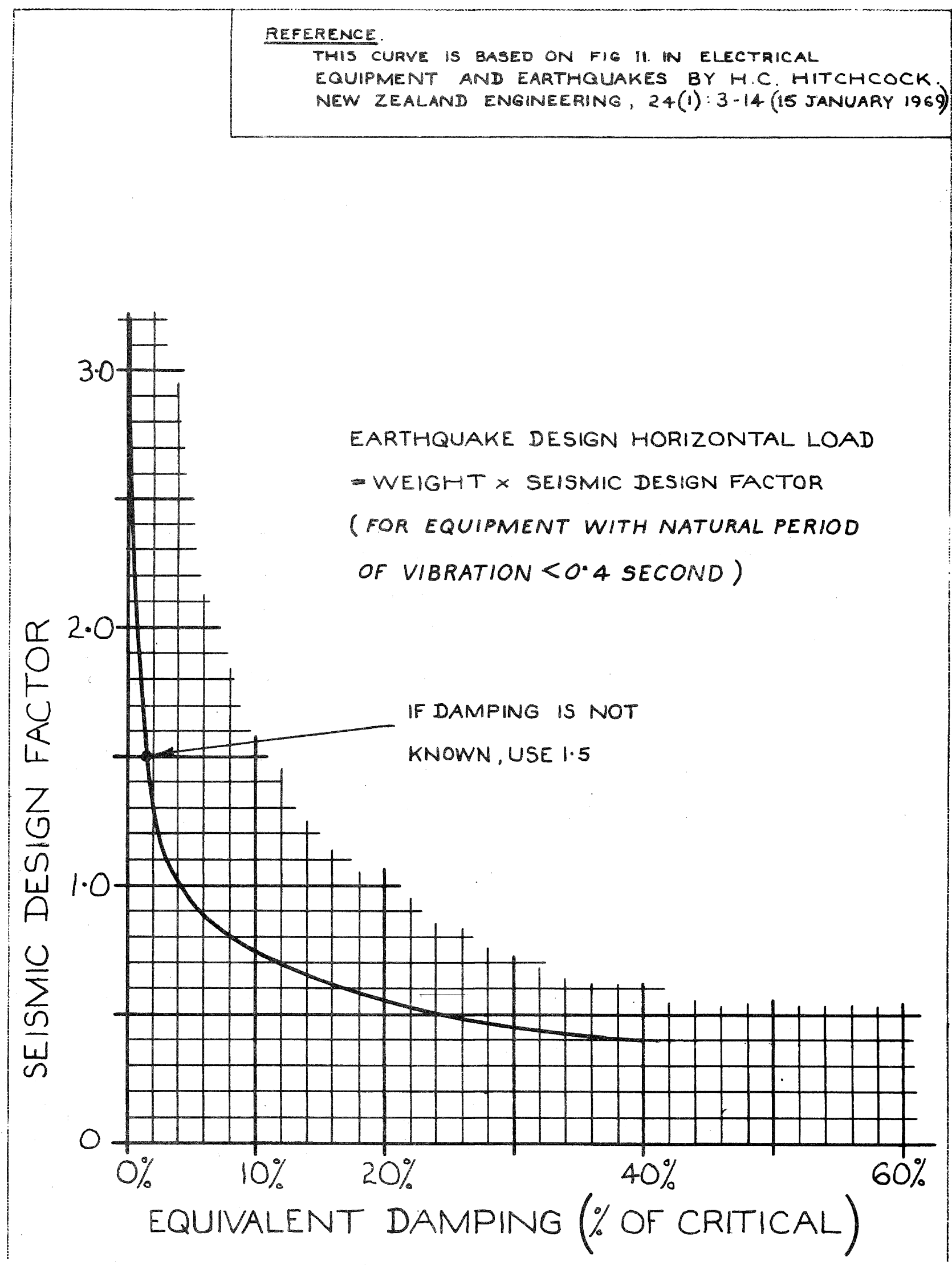

FIGURE 2: Seismic Design Factors for Brittle Equipment

Period less than $0.4 \mathrm{sec}$.

(NZED Specification Drawing Z 5396). 
Seismic Design Factor.

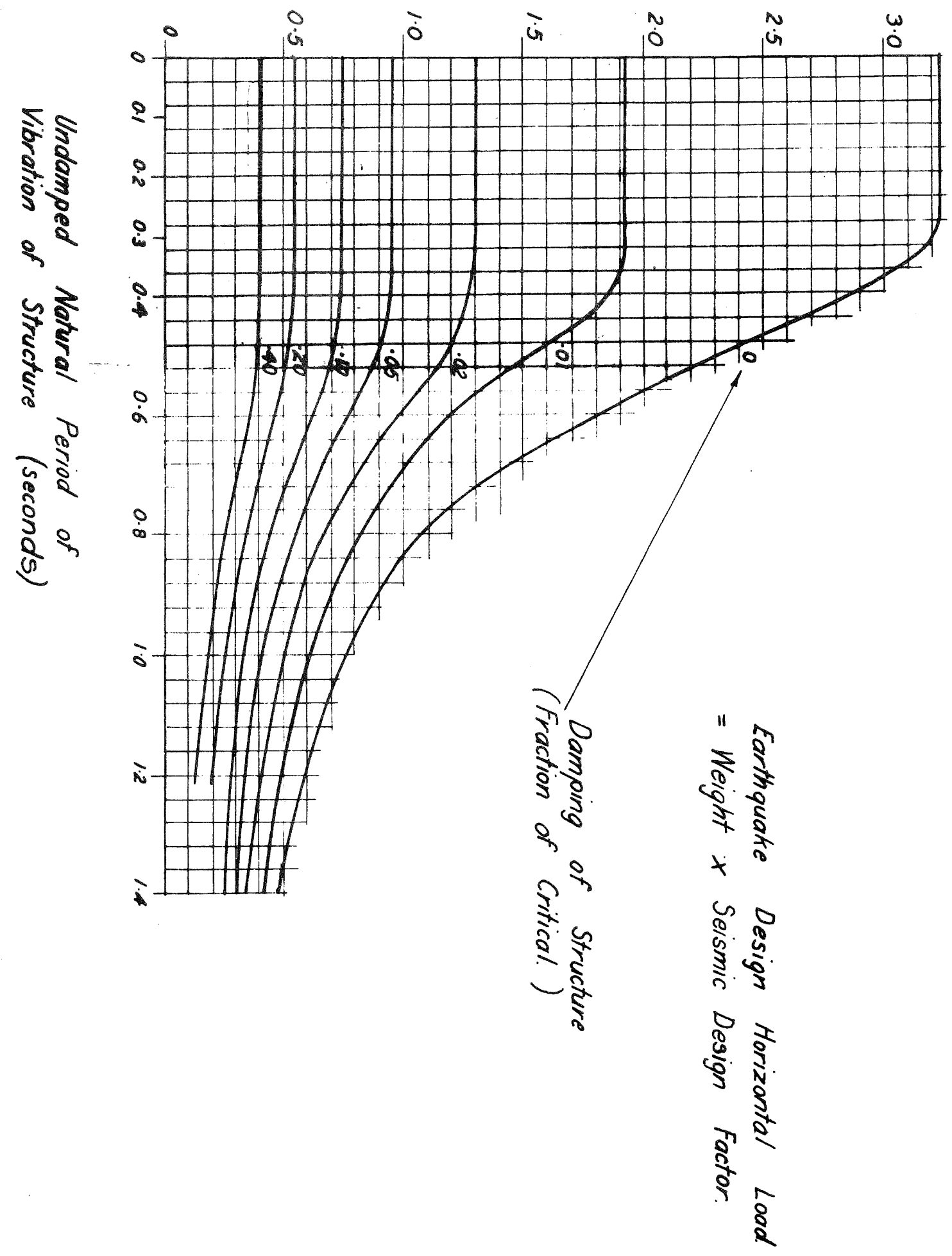

i $30^{\circ}=18$

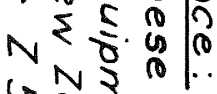

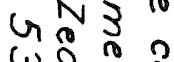

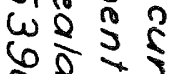

230 o

0
3

${ }^{n} \mathrm{R} ?$

की है

3.

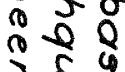

ว. डe $\pi$ is

सें

1
$-x 9$

1.5
1.25

जं

这走交

ว

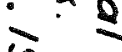

2

6 
$\vec{\omega}$

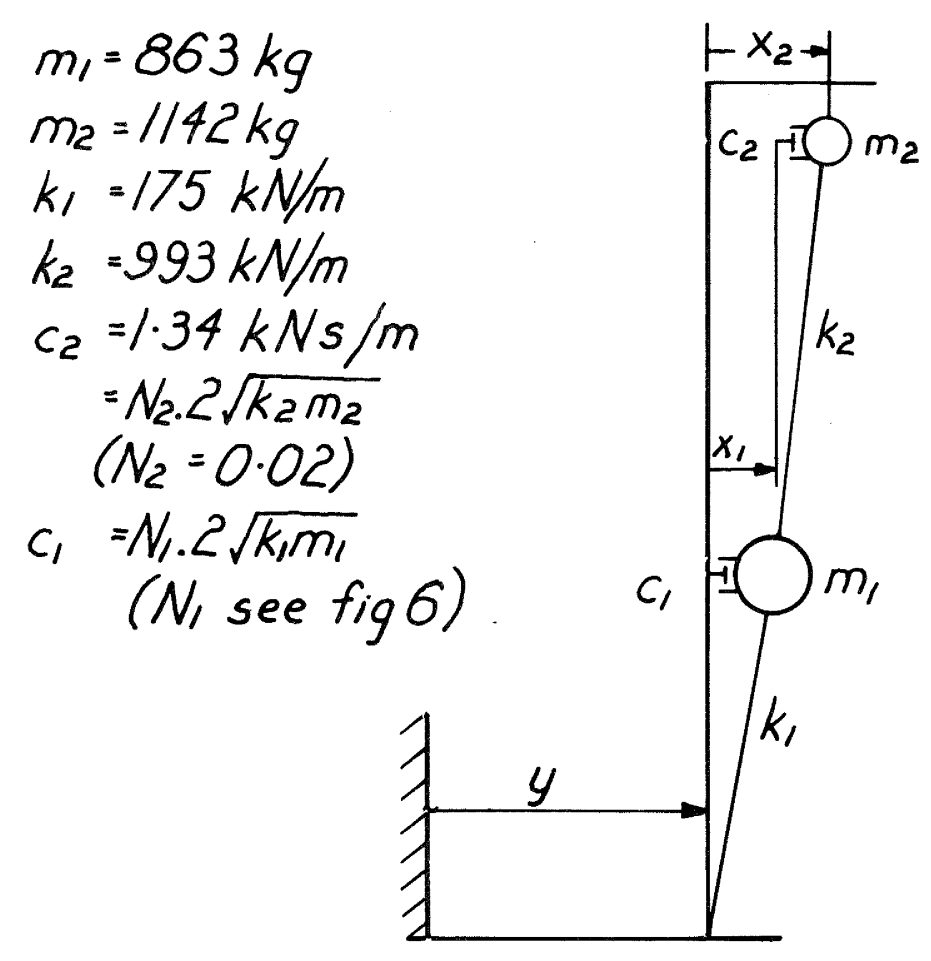

Simultaneous differential equations describing motion of masses $m_{1}+m_{2}$

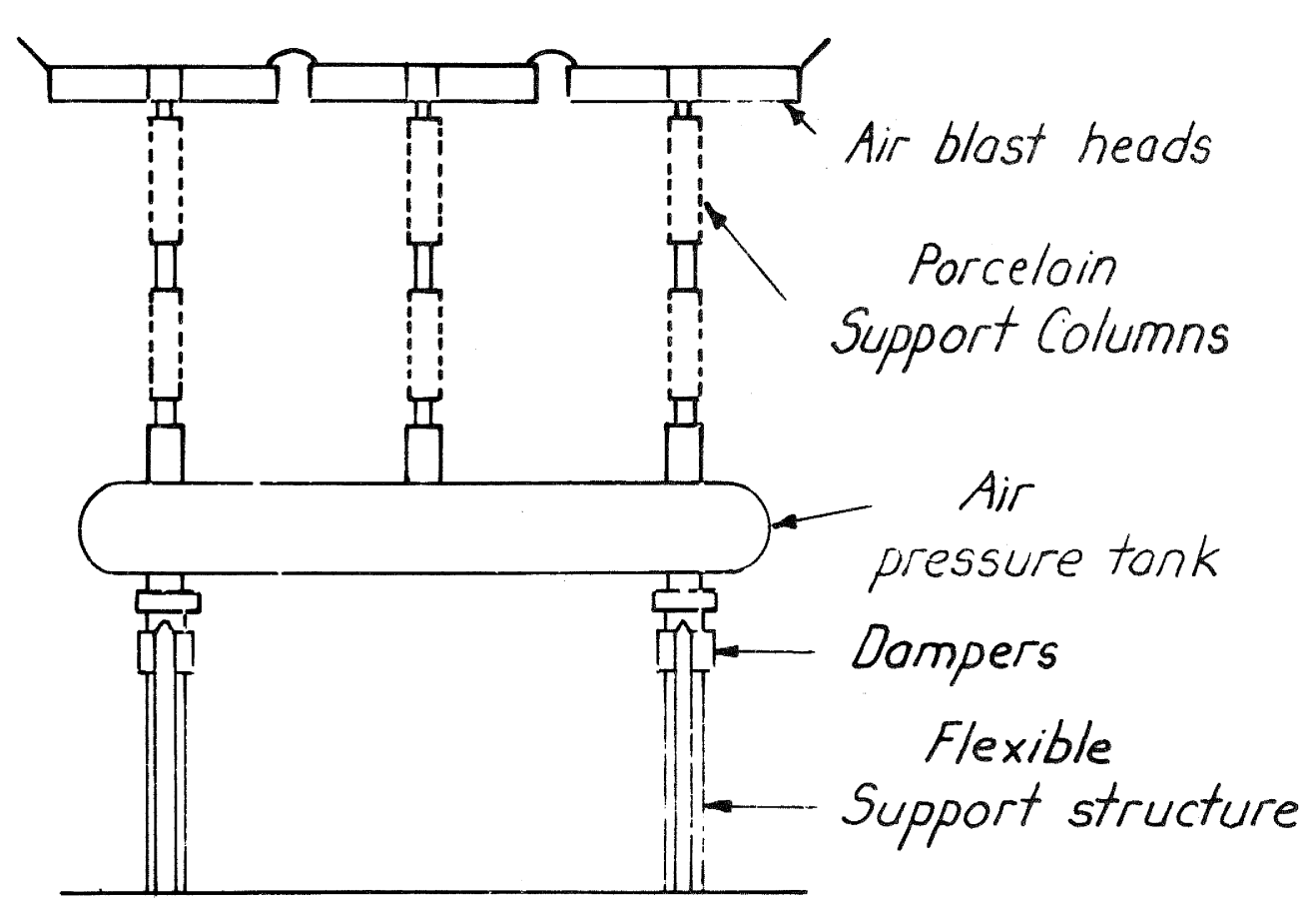

Single Pole of Circuit Breaker

$$
\begin{aligned}
& \ddot{x}_{1}=\left[-m_{1} \ddot{y}+c_{2} \dot{x}_{2}+k_{2} x_{2} \cdot\left(c_{1}+c_{2}\right) \dot{x}_{1}-\left(k_{1}+k_{2}\right) x_{1}\right] / m_{1} \\
& x_{2}=\left[-m_{2} \ddot{y}-c_{2} \dot{x}_{2}-k_{2} x_{2}+c_{2} x_{1}+k_{2} x_{1}\right] / m_{2}
\end{aligned}
$$

FIGURE 4: 220kV Circuit Breaker Outline, Mathematical Model as Two Body Problem and Differential Equations of Motion. 


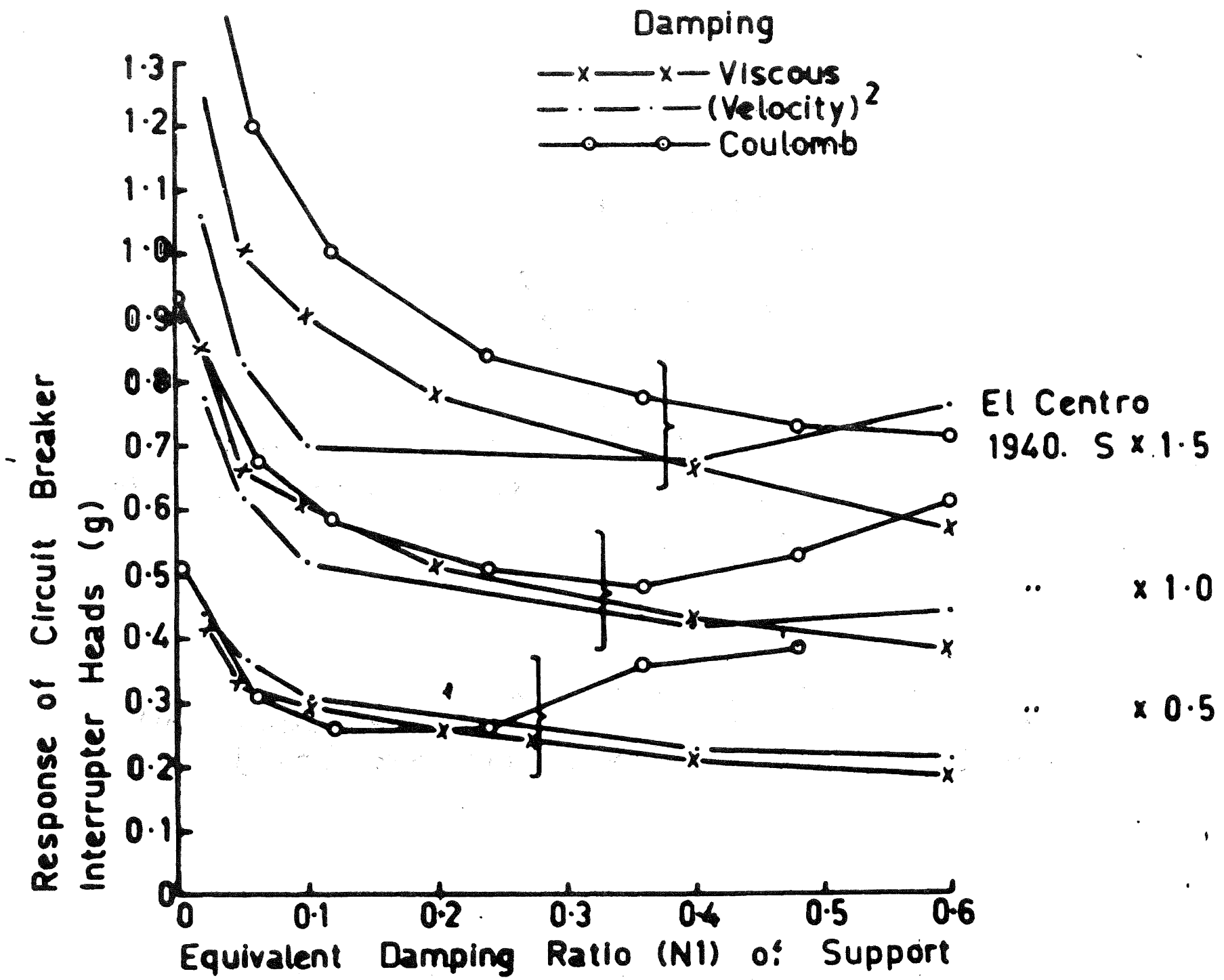

FIGURE 5. Acceleration Response of Circuit Breaker Blast Heads to El Centro 1940 NS Earthquake (max. ground acceleration .32g). 


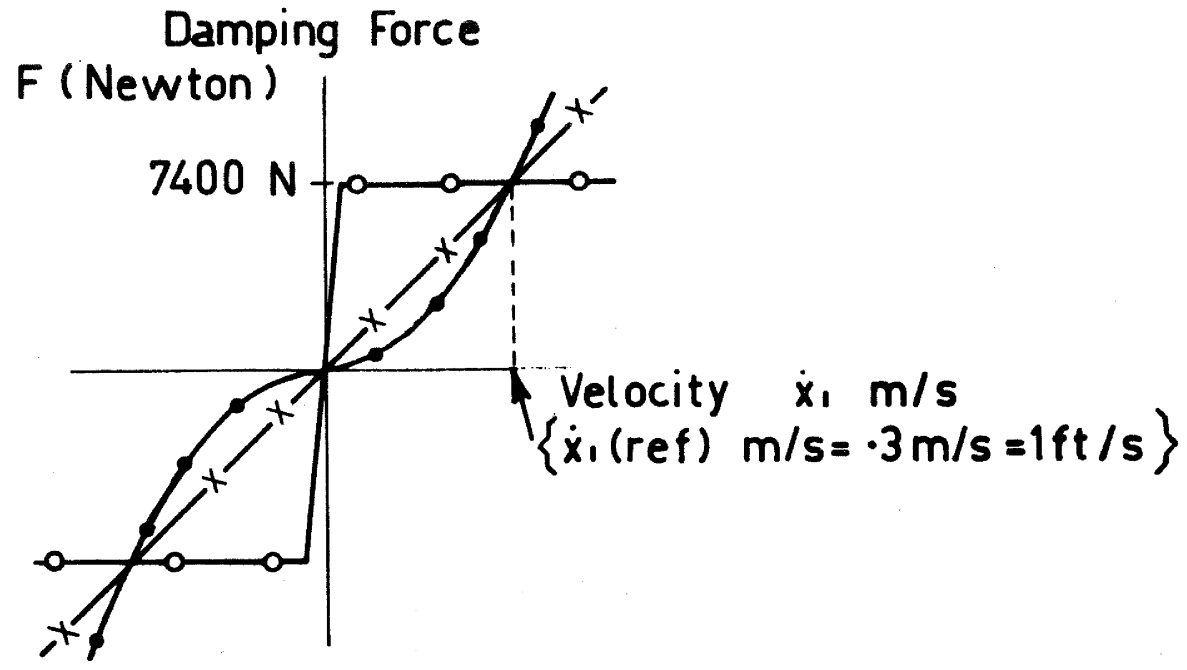

for Viscous Damping $F=2 N_{1}, m_{1} W_{1} \dot{x}_{1}$ for (Velocity) ${ }^{2} \quad F=2 N_{1}($ eq $) \cdot m_{1} w_{1} \dot{x}_{1}($ ref $)\left[\left(\dot{x}_{i}\right)\left|\dot{x}_{1}\right| / \dot{x}_{1}(\right.$ ref $\left.)\right]$ for Coulomb " $\quad F=2 N_{1}(e q) \cdot m_{1} w_{1} \dot{x}_{1}(r e f)\left[s i g n \dot{x}_{1}\right]$

FIGURE 6: Definition of Viscous and Non-linear Damping. 

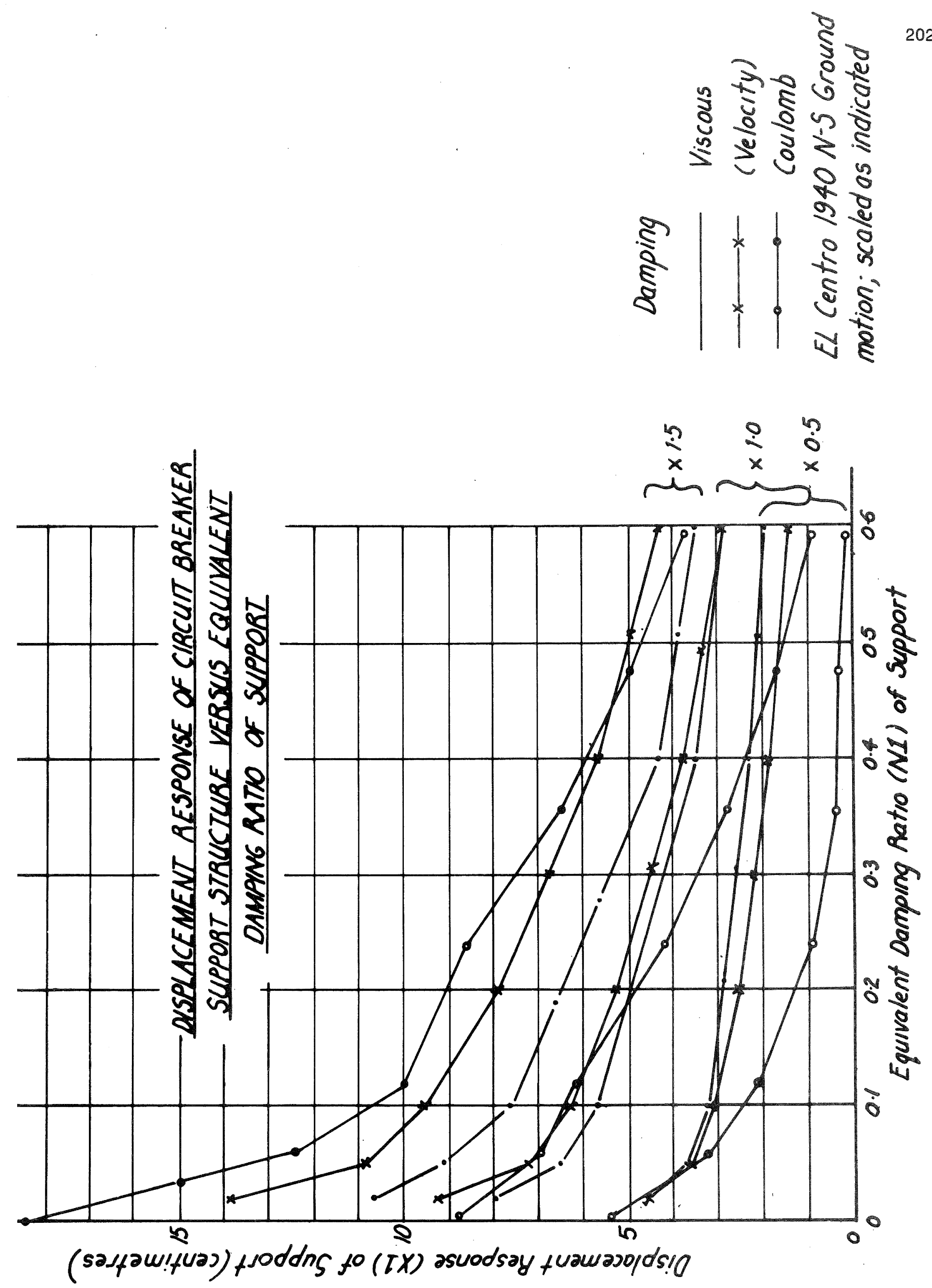

FIGURE 7: Displacement Response of Circuit Breaker Tank to EI Centro 1940 NS Earthquake. 
(A). ORIGINAL SUPPORT SYSTEM SEISMK FACTOR $=0.25 \mathrm{G}$.

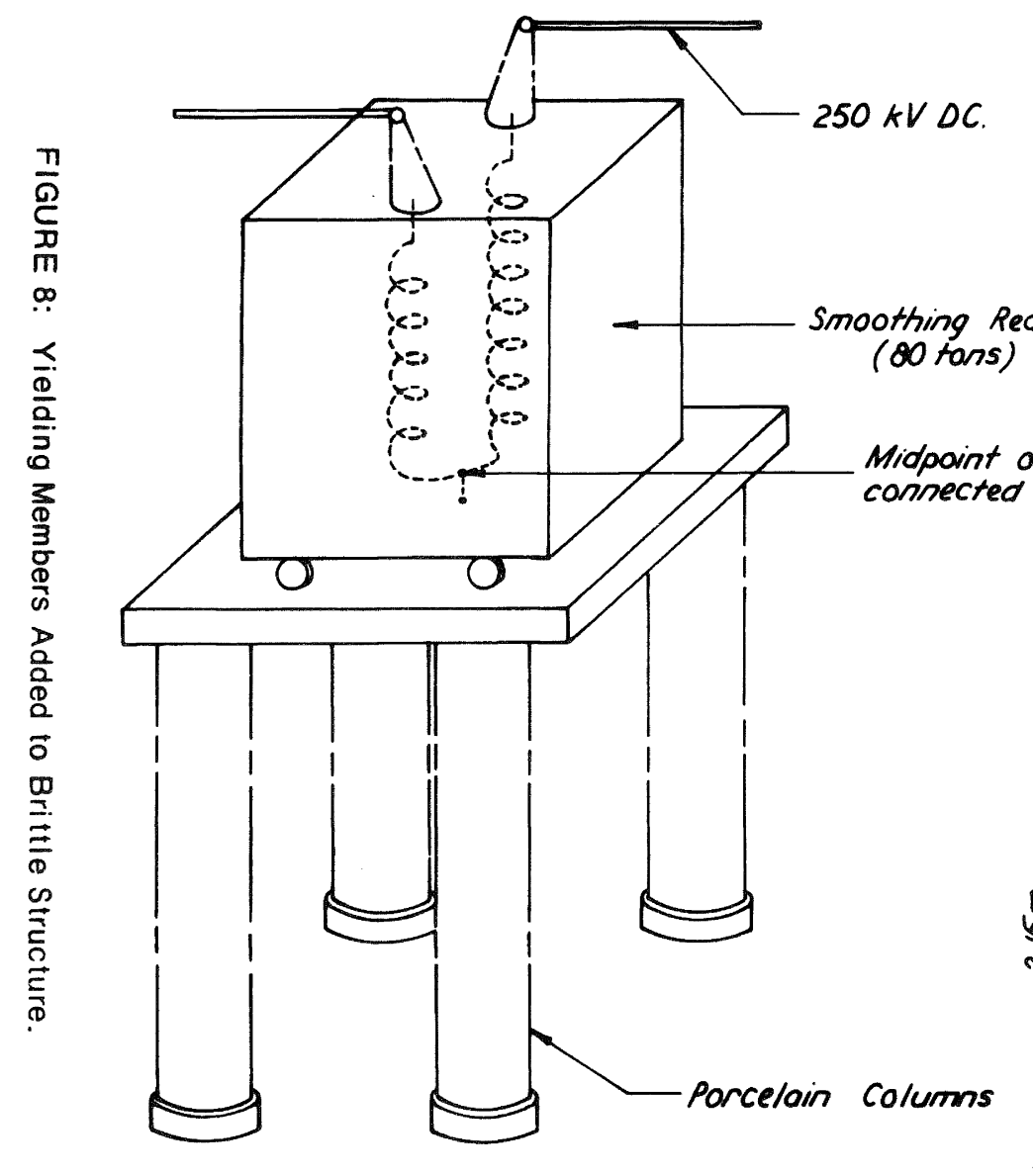

(B). MODIFIED SUPPORT SYSTEM

YIELD ACCELERATION $=0.226$
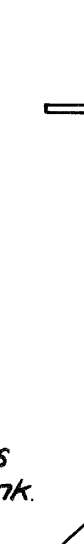

P
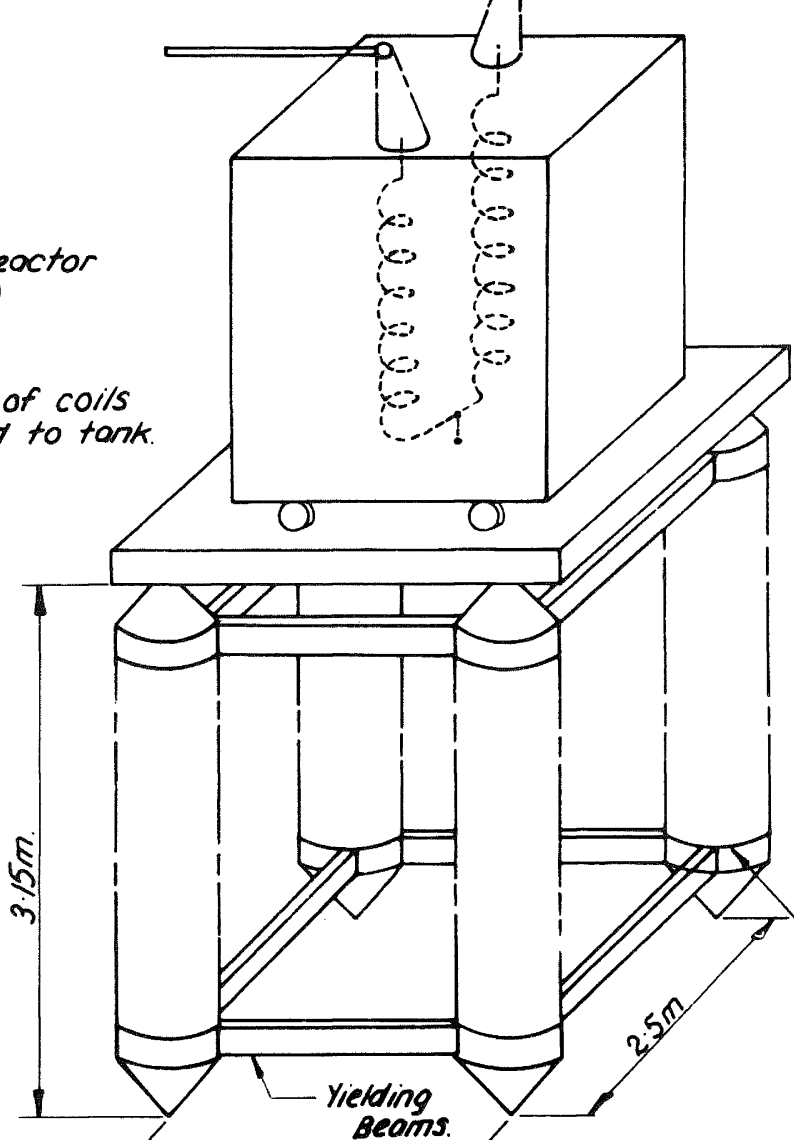

(

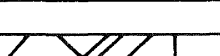

Y
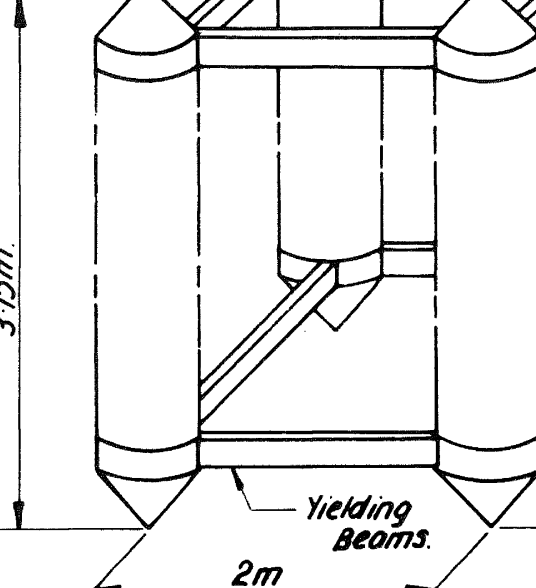

(C) ACTION UNDER EARTHQUAKE

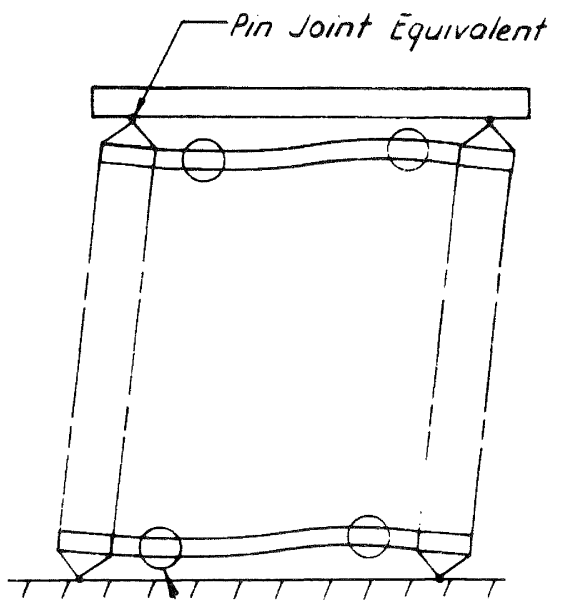

- Plostic Hinges - Yield moment of hinges less than frocture moment of columns.

Note.

Surge divertors not shown an this diagram 


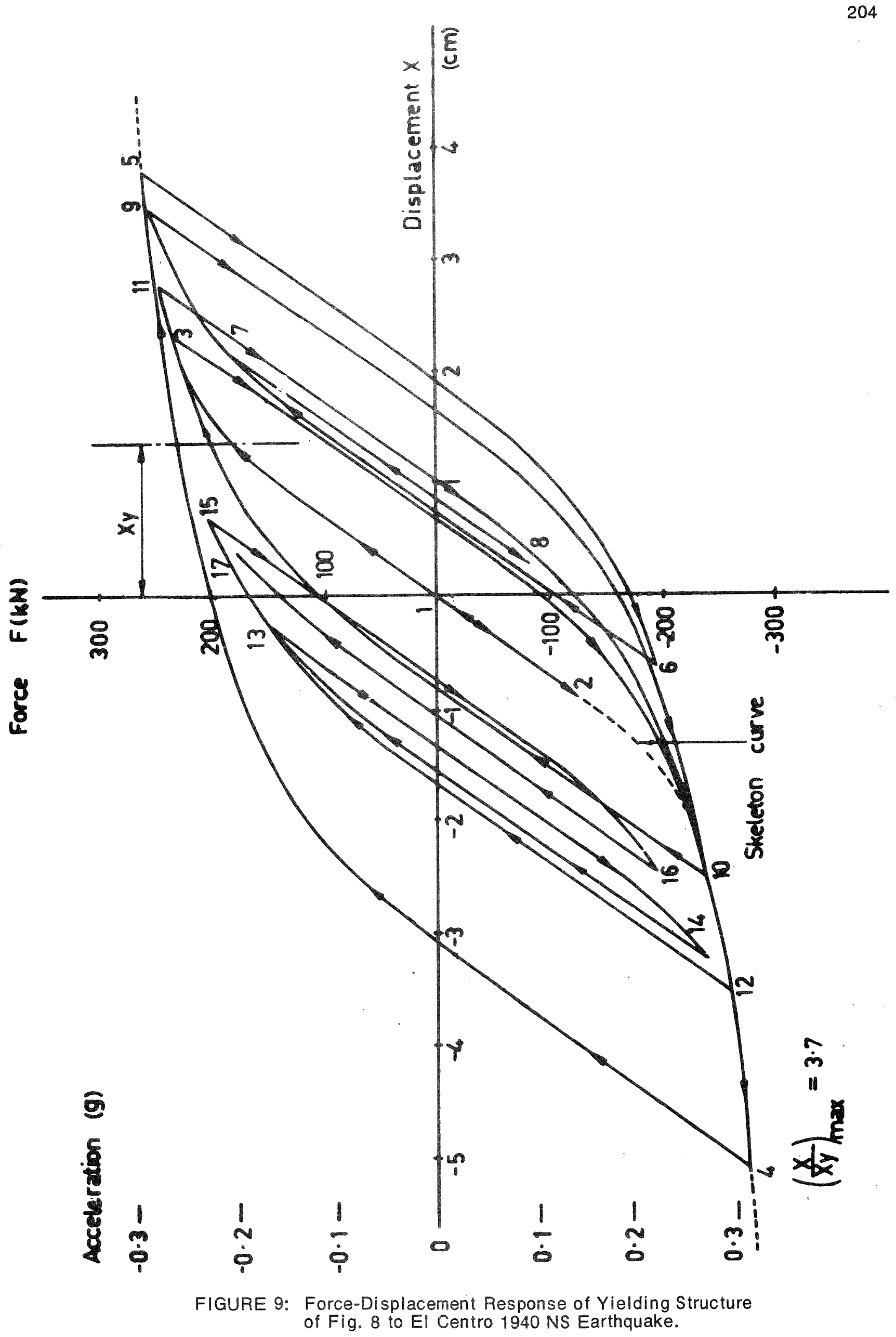




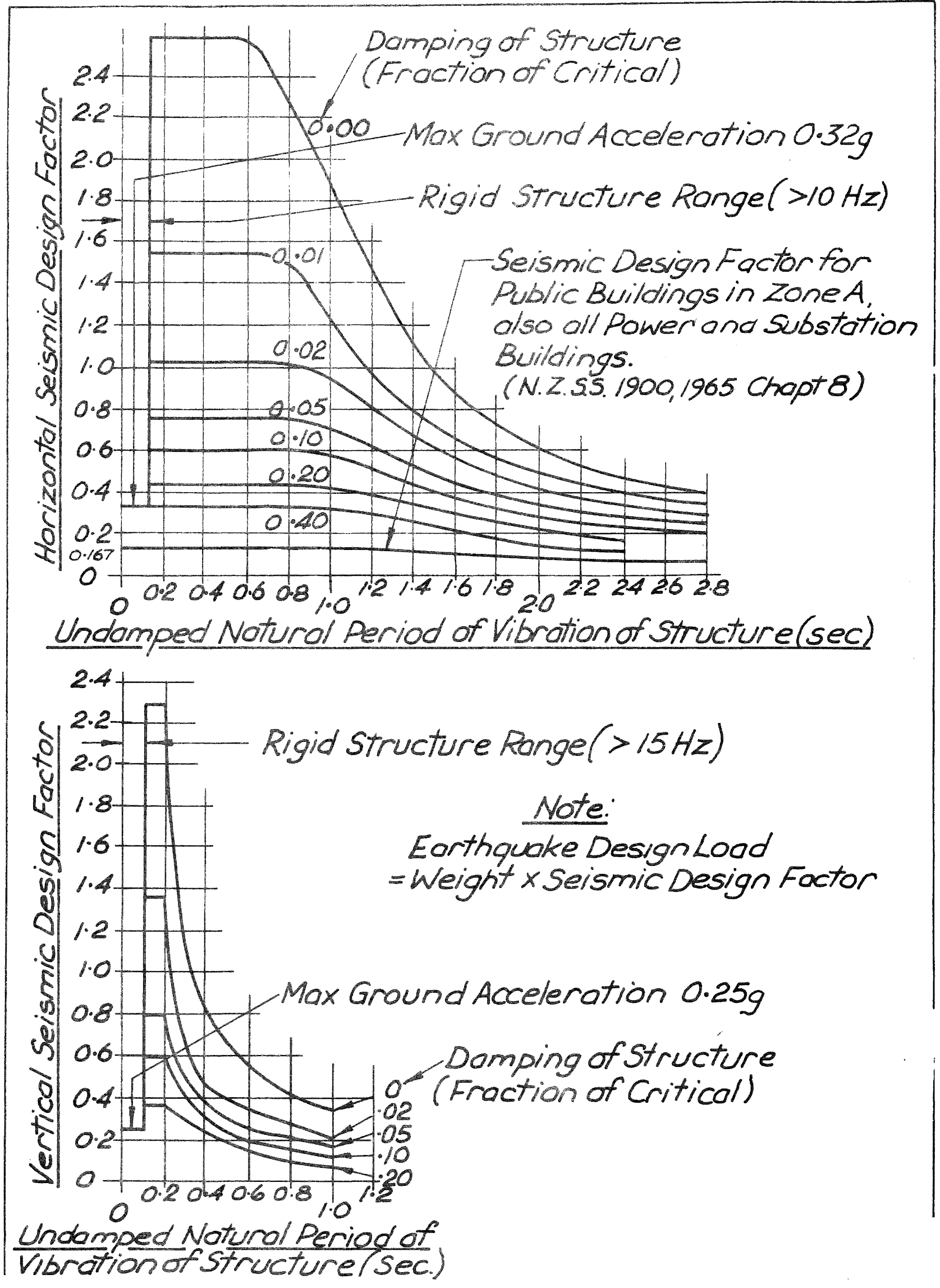

FIGURE 10: Special Earthquake Design Spectra - Huntly Power Station (NZED Specification Drawing Z 5590). 


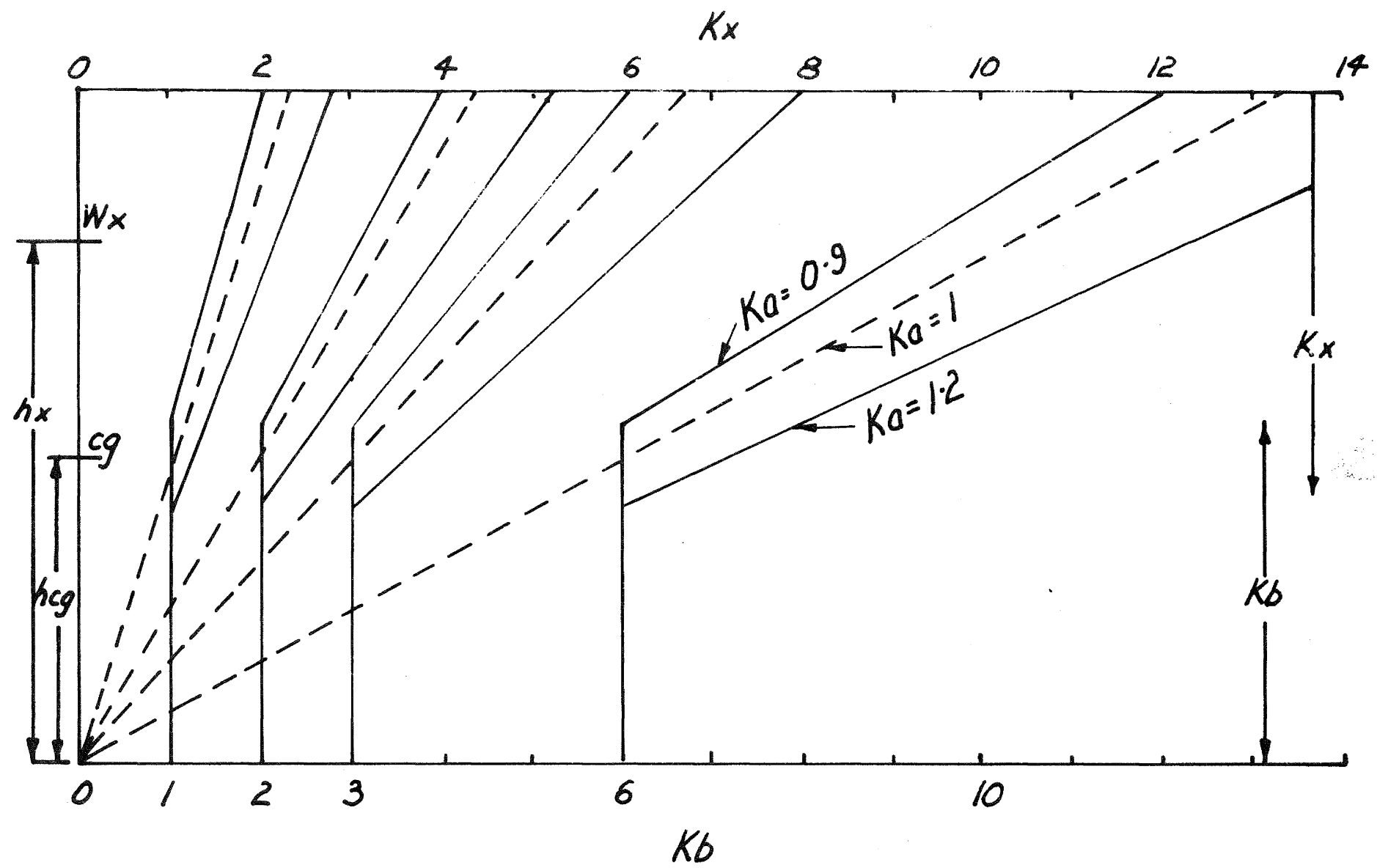

\section{FIG.II. SEISMIC FORCE FACTORS AS TABLE II}

FIGURE 11: Seismic Force Factors $K_{B}$ and $K_{x}$ for Portions of Structures and Miscellaneous Plant and Equipment (NZED Specification for Huntly Power Station Steam Raising Equipment). 


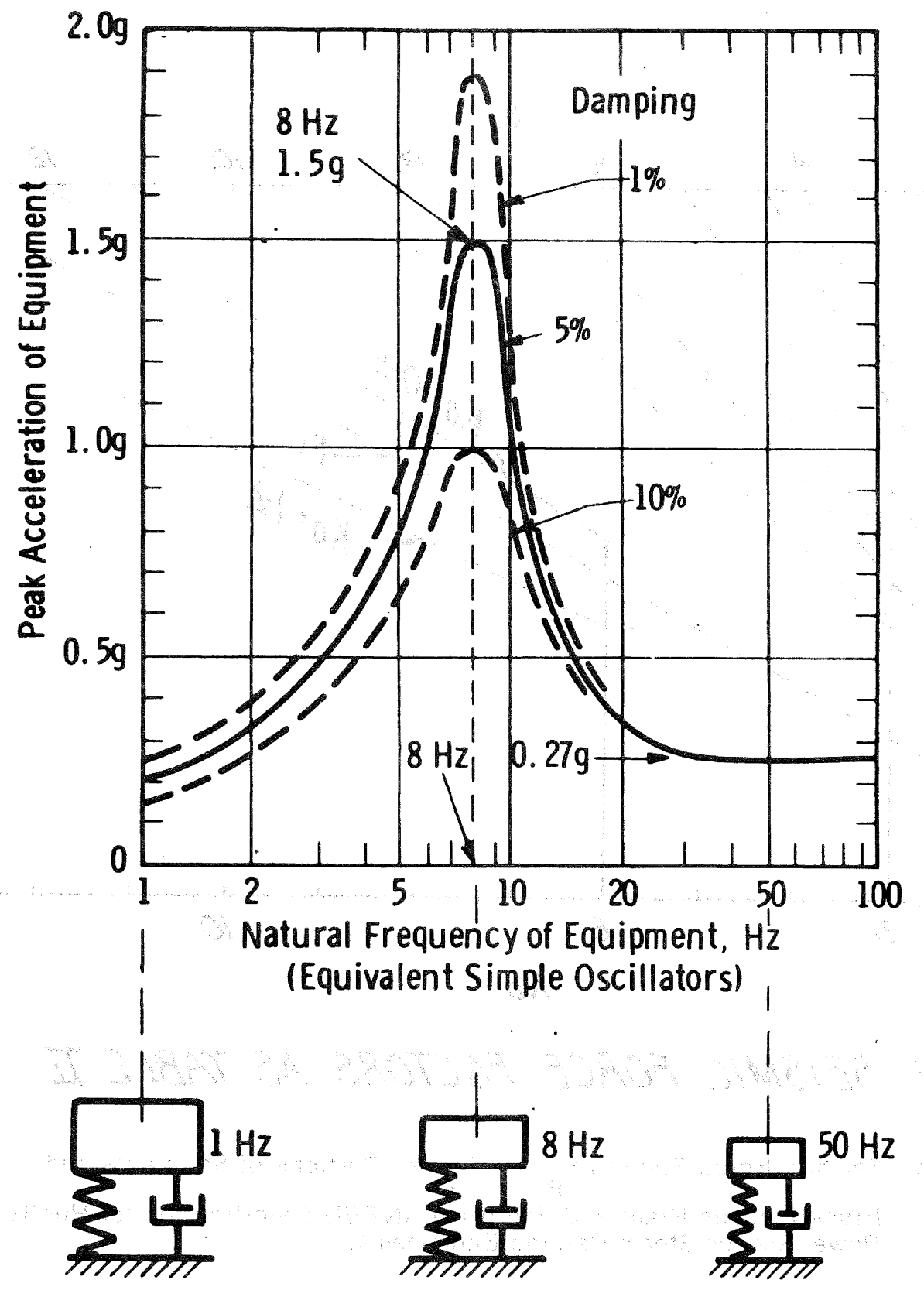
FIGURE 12: Floor Response Spectra for Equipment in an $8 \mathrm{~Hz}$ Building
(from Ref. 22). 